\title{
Integrating in-situ monitoring data and slope stability analysis for a new empirical slope failure warning criteria
}

\author{
Kuo-Jung Wang ${ }^{1}$, Der-Her Lee ${ }^{1}$, Yun-Che Chen ${ }^{1}$, Jian-Hong Wu ${ }^{1, *}$, Zhi-Ren Tseng ${ }^{1}$, and \\ Charng-Hsein Juang ${ }^{2}$ \\ Department of Civil Engineering, National Cheng Kung University, Tainan City, Taiwan \\ ${ }^{2}$ Department of Civil Engineering and Institute of Applied Geology, National Central University, Taoyuan City, Taiwan
}

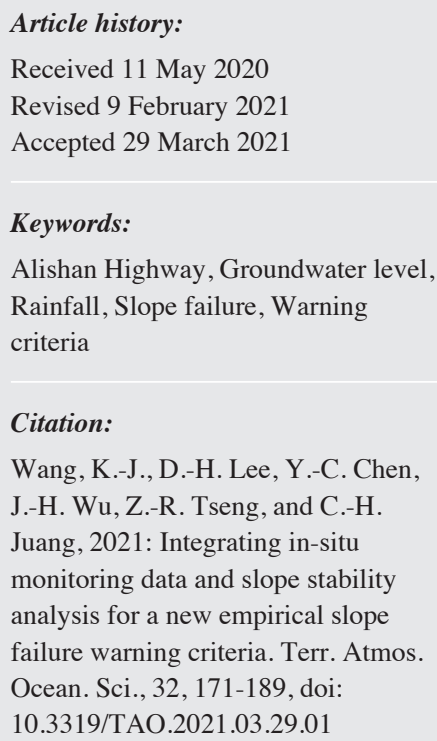

\begin{abstract}
This study investigated a highway slope $2 \mathrm{~km}$ ahead of the entrance of the Alishan National Forest Recreation Area, at the mileage of $86 \mathrm{~km}$ and $950 \mathrm{~m}$ of the Alishan Highway, Taiwan. Countermeasures were conducted after a slope failure. Groundwater wells and inclination wells were installed on the slope. The new idea to improve the accuracy of the empirical rainfall-based criteria comes from developing the relations between rainfall and groundwater fluctuation by analyzing the local groundwater elevation and the rainfall data at the Alishan rainfall station. The potential failure surfaces for shallow collapse and deep-seated landslide in the slope and the relationships between the slope stability and the groundwater level were assessed using Geo-Studio. The variation of the groundwater level with the critical state of the slope were obtained. Based on the analysis results, in each kind of potential failure of shallow collapse and landslide, the total cumulative rainfall $(\Sigma R)$ corresponding to three slope stability states were determined: (1) safe, slope is stable, (2) dangerous, slope is possible failure $(0<$ failure possibility $<100 \%)$, and (3) disaster, slope will failure (failure possibility $=100 \%$ ). Finally, combine the three slope stability states for the shallow collapse and the deep-seated landslide, a rainfall-based slope failure warning criteria for the test slope on the Alishan Highway is set up to operate in five stages: (1) safety $(\Sigma R<440 \mathrm{~mm}),(2)$ alert $(440 \mathrm{~mm} \leq \Sigma R<580 \mathrm{~mm})$, (3) evacuated $(580 \mathrm{~mm} \leq \Sigma R<850 \mathrm{~mm})$, (4) disaster $(850 \mathrm{~mm} \leq \Sigma R<990 \mathrm{~mm})$, and (5) catastrophe $(990 \mathrm{~mm} \leq \Sigma R)$.
\end{abstract}

\section{INTRODUCTION}

The climate change has increased the frequency and the fatality of the natural disasters all over the world. Haque et al. (2019) indicated that the extreme rainfall increases the occurrence of deadly slope failures from the global point of view. Therefore, developing the rainfall-based warning system is gaining increasing attention to answer the urgent requirement to safeguard the tourists along the San Francisco Bay Area Highways, USA (Wilson 1997), middle mountain, Nepal (Merz et al. 2006), China (Zhang et al. 2011), and different countries all over the world (Guzzetti et al. 2020).

Taiwan has geologically young formations fractured by plate tectonic activities, and it is therefore prone to land-

\footnotetext{
* Corresponding author

E-mail:jhwu@mail.ncku.edu.tw
}

slide and debris flows during seasons of torrential rain. The Alishan Highway (Tai-18 Highway) in Chiayi is the main route to the National Alishan Froest Recreation (NAFR) area, which is a well-known tourist attraction in Taiwan. However, the Typhoon Herb (1996) and Morakot (2009) have significantly impacted to the Alishan area. During the Typhoon Morakot, the 48-h, 72-h, and total cumulative rainfall are 2361,2748, and $2884 \mathrm{~mm}$ at Alishan rainfall station. These rainfall data exceeded the return period of 2000 years and the 48-h and 72-h cumulative rainfall approach to the world record (Shieh et al. 2009). Typhoon Morakot also induced 26 slope failures and $15342 \mathrm{~m}^{3}$ failure deposits at the high altitude section $(78.8-96 \mathrm{~km})$ of the Alishan Highway. Similarly, the Typhoon Herb triggered 21 slope failures and created failure deposits of $70217 \mathrm{~m}^{3}$ (Lee et. al. 2013). Since the highway slopes fail during the rainy 
season, the forest recreation area could be isolated and the traffic in the neighboring areas between Chiayi and Nantou can be shut down. Therefore, many efforts are concentrated on investigating the slope safety of the Alishan Highway to safeguard the tourists and local residents.

$\mathrm{Hu}$ and Liao (2010) developed an up-slope mitigation priority model using an artificial intelligence skill for Alishan mountain road. This model is developed based on Bayesian classification theorem, historical rainfall and landslide data, and an artificial intelligence technology: Gaussian process. The parameters needed for this model include the up-slope features, lithology, catchment area, vegetation coverage, and rainfall data. Rainfall is considered to be the triggering factor of landslide among these parameters in this study. Chi and Lee (2013) developed an empirical formula to estimate the rainfall triggered landslide volume along the Alishan Highway. If the highway slopes fail during the rainy season, the forest recreation area could be isolated, especially near the entrance to the NAFR area, and the traffic in the neighboring areas between Chiayi and Nantou can be shut down.

The rainfall-based warning criteria of slopes are usually divided as empirical model and physical model. In the empirical model (Lin et al. 2009; Chang et al. 2011; Lee et al. 2013), warning threshold is the boundary with/without slope failure based on rainfall parameters (rainfall intensity, cumulative rainfall, or rainfall duration) from the neighboring rainfall station. Regarding the physical model, Huang et al. (2012) measured the water pressure profile in an Alishan highway slope at Five Turn Point using an array of pressure sensors and demonstrated the possible incorporating into the existing mechancis-based analytical model. The groundwater level in the slope is the dominating factor of the slope stability. Because monitoring rainfalls on the slopes is easier than monitoring groundwater level in each slope, the empirical model is suitable to manage slopes along a mountain highway regionally but the physical model is useful to clarify the stability of a special slope. In addition, the empirical model is based on statistical analysis with less physical meaning than the physical model.

In this study, firstly, we attempt to investigate the relationship between the "regional" rainfall and groundwater level of the "specific" test slope. And then, use the slope stability analysis to connect the groundwater level with the safety factor of the "specific" test slope. Finally, an "empirical" and "regional" rainfall-based slope failure warning criteria for the "specific" test slope is established at the mileage of $86 \mathrm{~km}+950 \mathrm{~m}$ on the Alishan Highway.

\section{DESCRIPTION OF THE TEST SLOPE}

\subsection{Location and Topography}

The test site is the upper slope at $86 \mathrm{~km}$ and $950 \mathrm{~m}$ on the Alishan Highway. Near the slope toe, the altitude is $2071 \mathrm{~m}$ above sea level, and is marked by the red dashed line in Fig. 1. The Alishan Highway is starting from the Chiayi Station of the Taiwan High-Speed Railway in Taibao, Chiayi County. The highway leads into the mountainous area from Chukou, Fanlu Township ( $34 \mathrm{~km}$, elevation of $280 \mathrm{~m}$ ). Figure 2a shows the topographic map of the test slope. The crown (scar) of the previous slope failure happened in 2011 is located at the elevation of $2088 \mathrm{~m}$. The part of slope crosssection new A-new A', o-a-b-c-f-d, in Figs. 2a and b shows the angles of the upper part of previous failure surface (ab) and the deposit zone at the lower slope (bc), which are 58.5 and $28.8^{\circ}$, respectively. Therefore, the original slope profile is assumed as an infinite slope, o-a-e-d, with a slope angle of $21.8^{\circ}$. The slope was excavated as a slope (e-c) with a slope angle of $60^{\circ}$ during the construction of the Alishan Highway. Then, in 2011, a torrential heavy rainfall triggered a shallow slope failure on the slope along the a-b line. The sliding rocks/soils deposited at the slope toe on the Alishan Highway. The attitude of the non-failure part of test slope (near BH-A, BH-B in Fig. 2a) is N60W/21.8SW. The previous shallow slope failure in 2011 had a width about $35 \mathrm{~m}$ and a height from the highway to the crown of the slope is $17 \mathrm{~m}$. The outcrop of the colluvium in the previous slope failure surface is shown in Fig. 2c.

\subsection{Geology of the Test Slope}

The previous shallow slope failure of the test slope occurred by a torrential heavy rainfall in 2011, and it was rehabilitated in 2013. In the construction of the slope failure countermeasures, four boreholes were drilled, and four inclinometer casings were installed into the slope. Figure 2a shows the position of the four boreholes: B1' (15 m), B2' (15 m), B3' $(10 \mathrm{~m})$, and B4' $(10 \mathrm{~m})$. In 2014, two additional 30-m boreholes, BH-A (at the elevation of $2101 \mathrm{~m}$ ) and BH-B (at the elevation of $2097 \mathrm{~m}$ ), were drilled into the upper part of the test slope as also shown in Fig. 2a.

The cores drilled from the six boreholes show that the test slope was covered by at least $30 \mathrm{~m}$ of sandstone colluvium. This colluvium slope may be formed by the ancient landslides in the Nanchuan Formation.

\section{IN SITU MONITORING OF THE TEST SLOPE}

A series of laboratory tests for physical properties such as unit weight, grain size distribution, and shear strengths of the colluvium were performed on the rock cores drilled from the test slope. The unit weight of the colluvium was determined to be $21 \mathrm{kN} \mathrm{m}^{-3}$, and the total shear strength parameters of the sliding plane within the colluvium by using direct shear test were $\mathrm{c}=12 \mathrm{kPa}$ and $\phi=33^{\circ}$. Each borehole (BH-A and $\mathrm{BH}-\mathrm{B})$ was also functioning as the inclination 


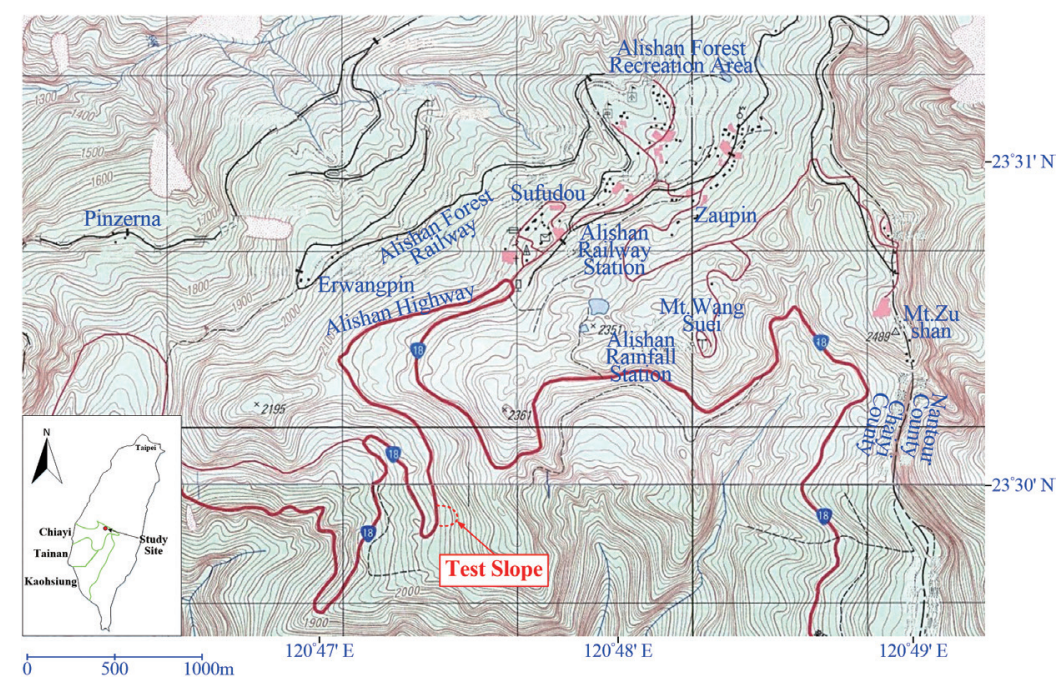

Fig. 1. The location of test slope on Alishan Highway (Taiwan-18 Highway) at the mileage of 86k+950.

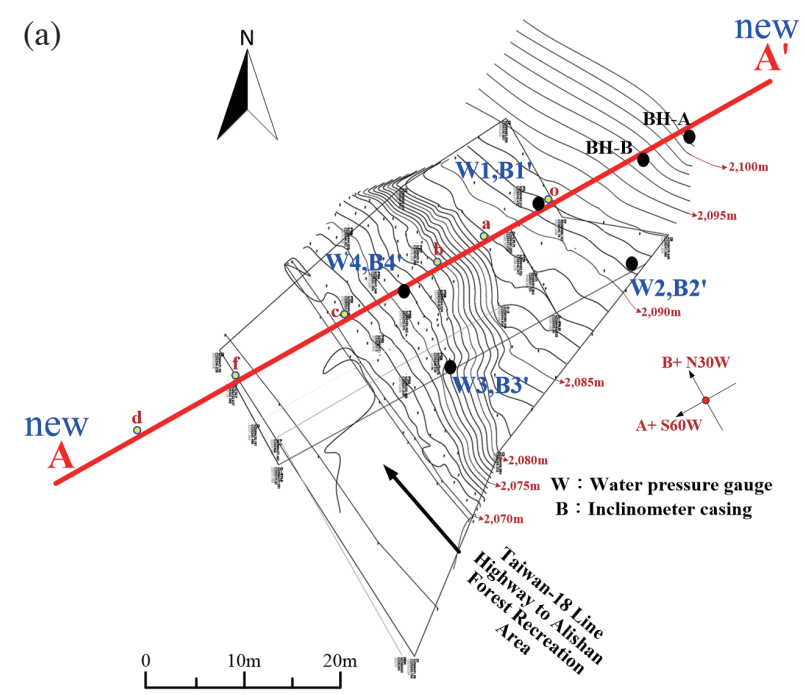

(b)

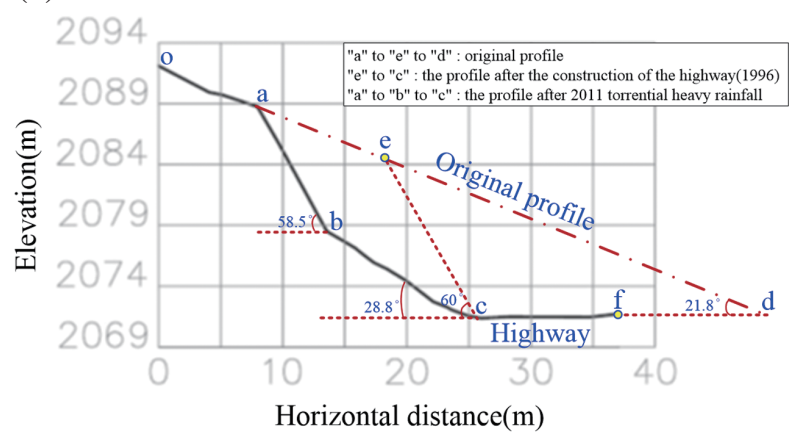

(c)

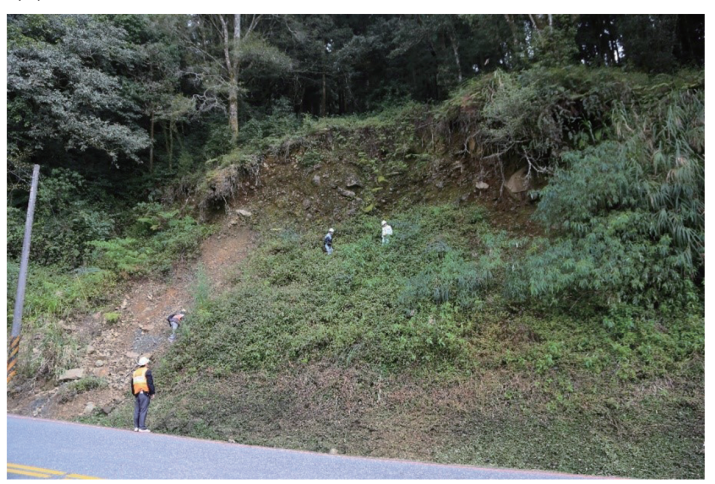

Fig. 2. (a) Topographic map of the test slope (replotted from Chen 2015); (b) Cross-section of new A-new A'; (c) Photo of profile a-b-c and colluvium outcrop. 
well and the groundwater well to monitor the slope movement and the groundwater level. However, the groundwater wells, W1, W2, W3, and W4 were installed separately to the inclinometer boreholes B1', B2', B3' and B4'.

\subsection{Slope Displacement Monitoring Results}

To monitor the subsurface movement of the test slope, inclinometer casings were installed in boreholes B1', B2', B3', B4', and BH-A, BH-B. Based on the sliding direction of the previous slope failure in 2011, the A-axis of the inclinometer casing was parallel to the previous sliding direction, with trend $\mathrm{S} 60 \mathrm{~W}$ for $\mathrm{A}+$ direction and the $\mathrm{B}$-axis was perpendicular to the A-direction with trend $\mathrm{N} 30 \mathrm{~W}$ for $\mathrm{B}+$ direction. The $\mathrm{A}+$ and $\mathrm{B}+$ directions are also displayed in Fig. 2a. In BH-A and BH-B, the inclinometer are installed to the depth of $30 \mathrm{~m}$. Based on the borehole drilling results, the thickness of the colluvium at the test slope exceeds $30 \mathrm{~m}$. The periodical monitoring of $\mathrm{BH}-\mathrm{A}$ and $\mathrm{BH}-\mathrm{B}$ began in March 2014 and ended in January 2018 (Figs. 3a and b). In Fig. 3a the inclinometer casing in BH-A deformed slowly in the negative A-direction and the positive B-direction. Similarly, in Fig. 3b, the inclinometer casing in BH-B also deformed in the negative A-direction with small swinging. It may be caused by the bad installations of the inclinometer casings in BH-A and BH-B.

However, the movement of the casing installed in Boreholes B1', B2', B3', and B4' were recorded during and after the construction of counter measure to stabilize the slope. Boreholes B1' and B2' were located at the upper part of the slope and near the crown of the previous collapse. Boreholes B3' and B4' were on the toe of the slope. Figure 4 shows the monitoring results of the inclinometer casing in Boreholes B1' to B4' from March 2014 to January 2018. The monitoring data indicated a potential shallow sliding surface passing through Boreholes B1' and B2' at $1 \mathrm{~m}$ below the ground surface, and the potential sliding surface also extended to Boreholes B3' and B4' at a depth of $5 \mathrm{~m}$.

\subsection{Records of the Groundwater Level and Rainfall}

The installations of groundwater monitoring wells W1 to W4 in Fig. 2a are installed separately and are few meters away from the inclinometer wells, B1' to B4'. In W1 to W4, 2 inch PVC stand pipes are installed in the boreholes with $2 \mathrm{~m}$ vertical screen intervals through the pipes covered by the non-woven cloth outside with infill between borehole and non-woven cloth. However, the groundwater monitoring in $\mathrm{BH}-\mathrm{A}$ and $\mathrm{BH}-\mathrm{B}$ are combined with the inclinometer monitoring. Four $3 \mathrm{~mm}$ in diameter holes were drilled along the periphery of the 2 inch ABS inclinometer casing at the bottom section of $3 \mathrm{~m}$ from the bottom of the pipe with vertical interval of $10-20 \mathrm{~cm}$. Then, the pipes are covered by non-woven cloth and are installed in the bore- holes with infill between borehole and non-woven cloth. Figures $5 \mathrm{a}, \mathrm{b}$, and $\mathrm{c}$ show the change in the groundwater levels in BH-A, BH-B and B1', B4' with the rainfall record obtained by the neighboring Alishan Rainfall Station of the Central Weather Bureau, Taiwan (2013 - 2018, https:// www.cwb.gov.tw/) from March 2014 to January 2018 for BH-A and BH-B, and from March 2013 to December 2015 for B1' and B4'. The piezometers were installed near the bottom of the wells. In Fig. 5a, rainfalls in the dry and rainy seasons significantly fluctuate the groundwater levels in BH-A and BH-B. In the dry season, the groundwater levels in boreholes $\mathrm{BH}-\mathrm{A}$ and $\mathrm{BH}-\mathrm{B}$ were down to an elevation of 2084 and $2071 \mathrm{~m}$, respectively. By contrast, in the rainy season, the groundwater levels in the two boreholes were up to a high elevation. It is about $2092-2093 \mathrm{~m}$ for BH-A, and is about $2088-2092 \mathrm{~m}$ for BH-B.

Therefore, the ratio of groundwater level variation in $\mathrm{BH}-\mathrm{A}$ and $\mathrm{BH}-\mathrm{B}$ during rainy season is about 1:2. The high groundwater variation in BH-B may be caused by the lateral stress release due to the previous shallow slope failure in 2011 to introduce additional fractures and increase the hydraulic conductivity to rock mass near the previous slope failure surface. Obviously, the distance from the crown of the previous failure to BH-B is closer than that of BH-A.

In addition, different groundwater fluctuation patterns are also available in BH-B (Fig. 5a), W1 (Fig. 5b), and W4 (Fig. 5c). The increasing pattern of the groundwater levels in BH-B and W1 during rainfalls is similar but not the groundwater level decreasing after rainfalls. Concave curves are available for BH-B after rainfalls but the insufficient depth of the W1 generates flat groundwater curves, whose elevation is near the bottom of the borehole, after rainfall. In addition, after comparing the groundwater level curves in W4 (Fig. 5c) to the BH-B (Fig. 5a) and W1 (Fig. $5 b)$, groundwater level curves in W4 show concave curves, which are similar to those in BH-B, after rainfalls. But, the very sharp groundwater variations during rainfalls in $\mathrm{BH}-\mathrm{B}$ (Fig. 5a) and W1 (Fig. 5b) are not available in W4 (Fig. 5c) because the groundwater level in W4 exceeds ground elevation and outflows.

The groundwater level data obtained from Borehole BH-B was used as the representative data of the test slope in this study because the effect of rainfall on the variation of the groundwater level in BH-B is more sensitive than that in BH-A (Fig. 5a).

In this study, we combined the inclinometer casing and groundwater observation well in BH-A and BH-B. The well combination is an economic approach but makes it difficult to confirm the appropriation of the infill between the borehole and the casing. The inclinometer data from the well with improper infill show abnormal shapes of inclinometer curves and annoy the correct location of the sliding surface. Therefore, interpretation from this kind of data should be very careful. 
(a) $\mathrm{BH}-\mathrm{A}$ colluvium $\mathrm{BH}-\mathrm{A}$

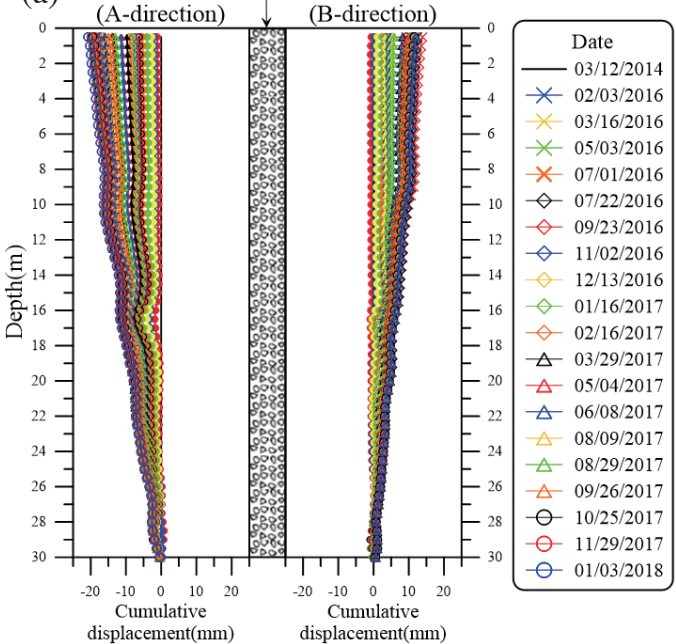

(b) BH-B colluvium BH-B

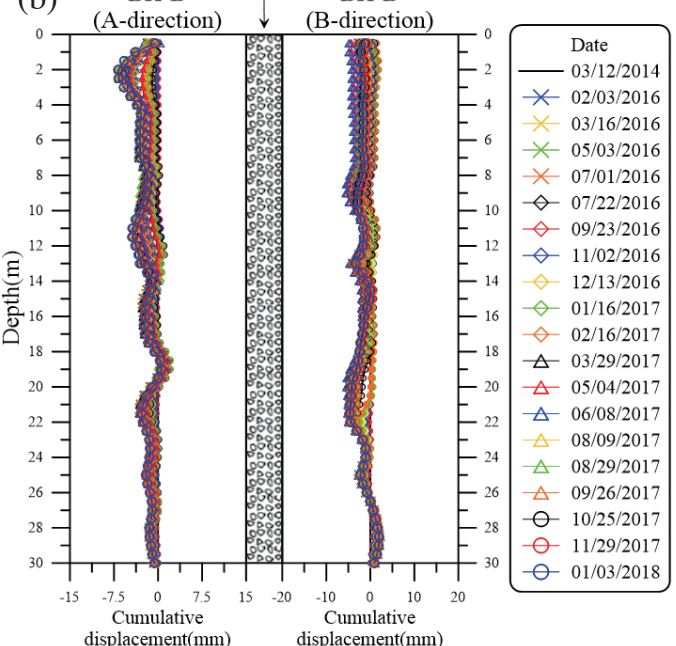

Fig. 3. The cumulative displacement of boreholes (a) BH-A and (b) BH-B (2014 - 2018).

(a) $\quad \mathrm{B} 1^{\prime} \quad$ colluvium $\quad \mathrm{B} 1^{\prime}$

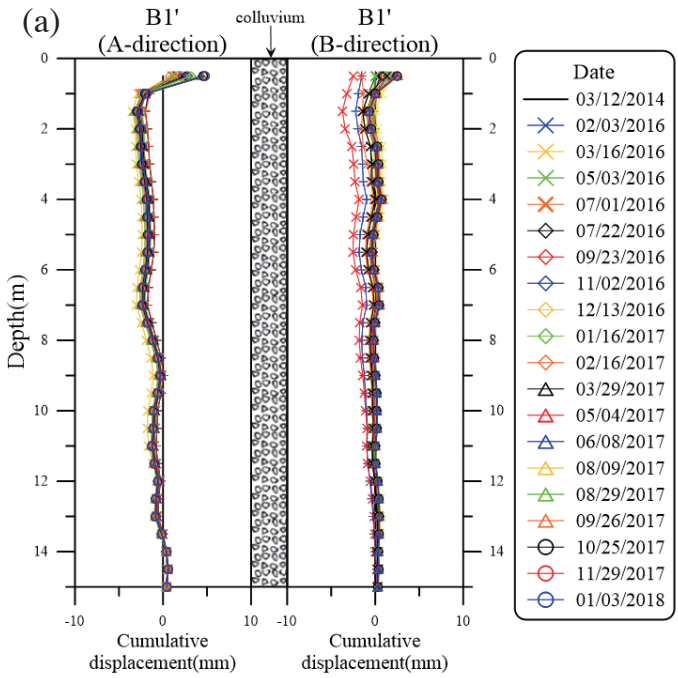

(c) $\underset{\text { (A-direction) }}{\mathrm{B} 3^{\prime}} \stackrel{\text { colluvium }}{\downarrow} \stackrel{\mathrm{B} 3^{\prime}}{\text { (B-direction) }}$

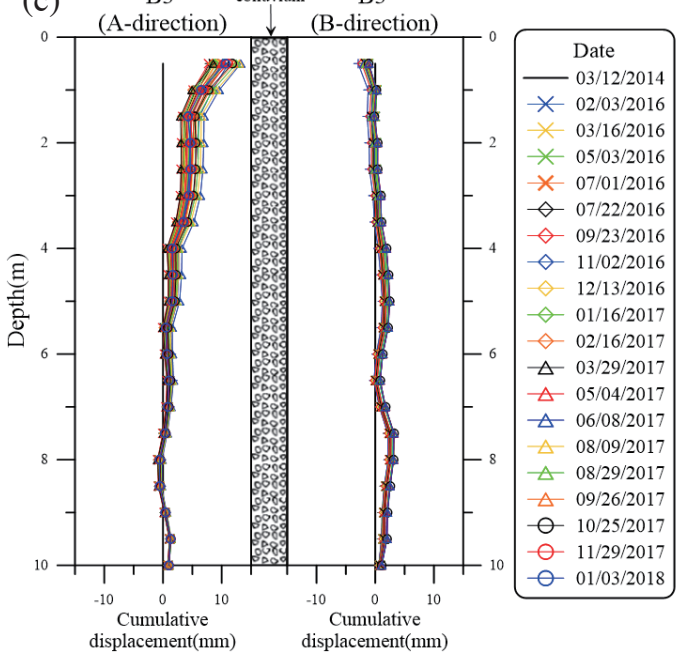

(b) B2' colluvium B2'

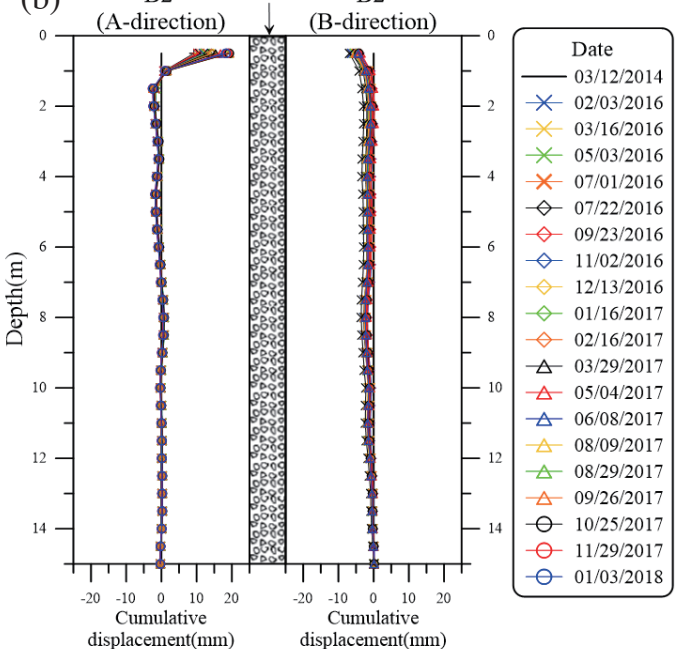

(d) $\quad$ B4' colluvium B4'

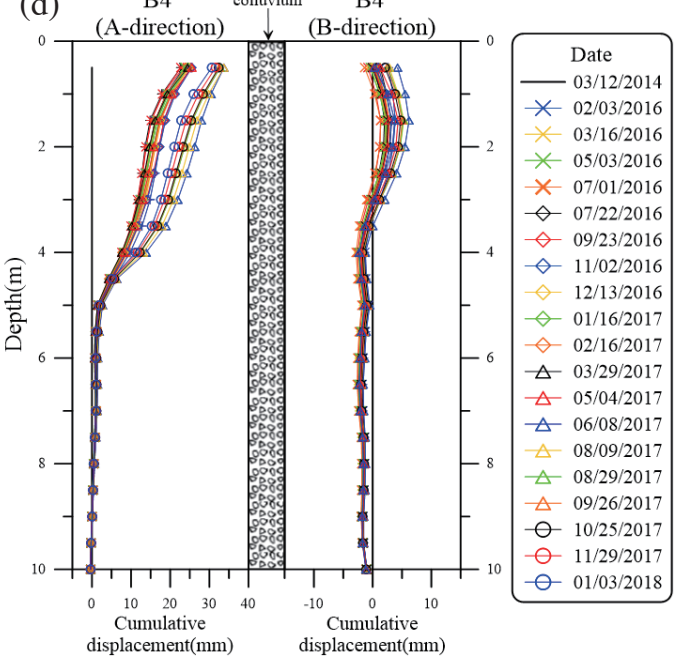

Fig. 4. The cumulative displacement of boreholes B1' to B4' (a) - (d). 


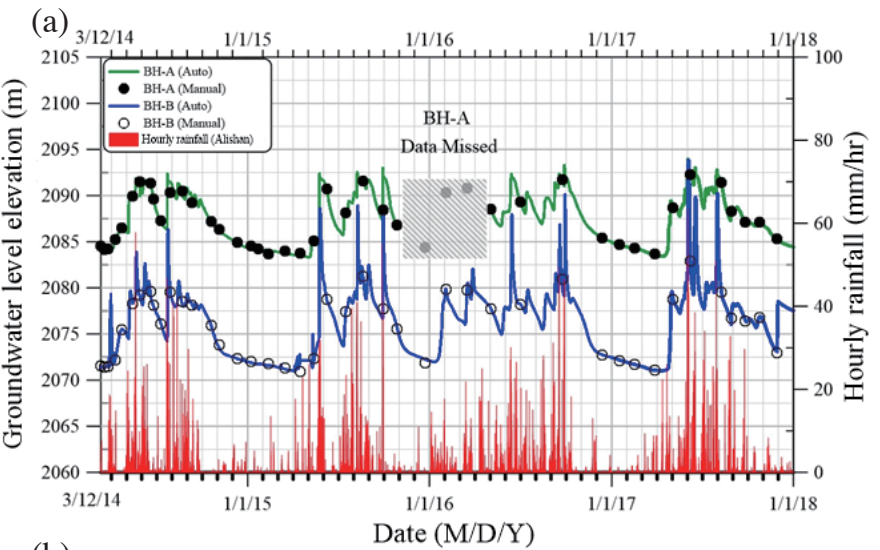

(b)

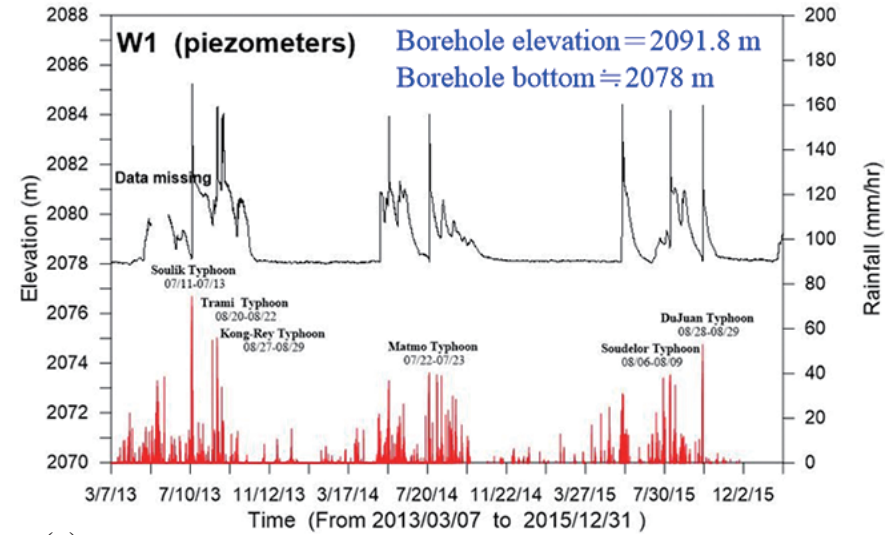

(c)

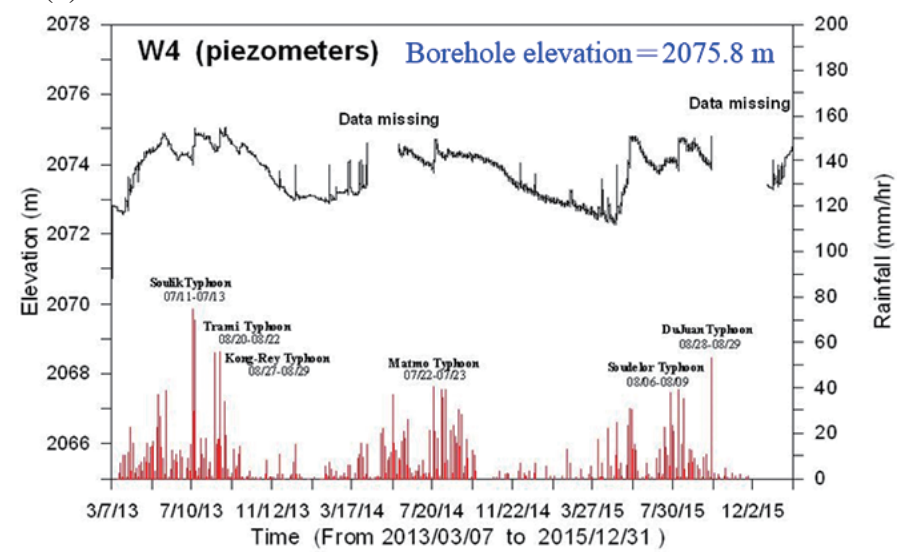

Fig. 5. Relationship between groundwater level fluctuation and rainfall of the test slope; (a) BH-A, BH-B holes (from March 2014 through January 2018); (b) B1' hole (from March 2013 to December 2015); (c) B4' hole (from March 2013 to December 2015). 


\section{RELATIONSHIP BETWEEN SLOPE STABILITY AND GROUNDWATER LEVEL}

In order to clarify the safety factor of the test slope as a function of the variation of groundwater level, the slope stability analysis was conducted along the new A-new A' profile of the slope (Fig. 2a) using SLOPE/W software in Geostudio (GEO-SLOPE International Ltd. 2012). In Table 1 (Chen 2018), the parameters for the slope stability analysis were obtained by a series of tests in laboratory and in field. Such as the physical property tests, direct shear test on the boring cores carried out in laboratory and the permeability test performed inner the borehole in field.

The first work of slope stability analysis was to find the potential sliding surface in the test slope. Based on the monitoring results of groundwater level (Fig. 5) and displacement of boreholes B1' and B4' (Fig. 4), we selected the lowest groundwater level in the dry season (elevation of $2084 \mathrm{~m}$ in BH-A and $2071 \mathrm{~m}$ in BH-B and B4') to analyze the location of the potential sliding surface in test slope.

The slope stability analysis showed two potential sliding patterns at the colluvium within $30 \mathrm{~m}$ below the ground surface:

(1) Shallow collapse (Fig. 6a): the first potential sliding surface passes 1 and $5 \mathrm{~m}$ below the slope surface of Boreholes B1' and B4', respectively, and extends to the slope toe.

(2) Deep-seated landslide (Fig. 6b): the second potential sliding surface passes $16.5 \mathrm{~m}$ below the ground surface in Borehole BH-A, and the bottom of Boreholes B1' and B4' and ends at the downslope of the Alishan Highway.

Since the variation of the groundwater level in the test slope changes the safety factors of the two potential sliding surfaces, it is necessary to investigate the relationship between the safety factor and the groundwater level. First, we selected the lowest groundwater level in the dry season (elevation of $2084 \mathrm{~m}$ in BH-A and $2071 \mathrm{~m}$ in BH-B and B4'). Then, due to the groundwater fluctuation differs in different boreholes, in each calculation step, we raised the groundwater level according to the groundwater fluctuation ratio of the boreholes, (Fig. 5) as the increment of $2 \mathrm{~m}$ in BH-B, $1 \mathrm{~m}$ in BH-A, and $0.2 \mathrm{~m}$ in B4', respectively, to carry out limit equilibrium analysis. Totally, 14 steps of raising groundwater level and calculating the corresponding safety factors of the two potential sliding surfaces had been carried out. The complete relationship between the groundwater level and the safety factors of the two potential sliding surfaces were obtained. Figure 7 shows the change in the safety factors of the first potential sliding surface (shallow collapse) and the second sliding surface (deep-seated landslide) for different groundwater levels. The groundwater level of BH-B is the representative groundwater level of the test slope in this study. When the groundwater level is raised to a critical point, the safety factor of the slope approaches to 1.0. In
Fig. 7, it shows that when the groundwater level raise, the safety factor of the first sliding surface (shallow collapse) will reduce to 1 in advance of the safety factor reduction of the second sliding surface (deep-seated landslide). The elevations of critical groundwater levels of BH-B in the two cases are 2089.0 and $2092.41 \mathrm{~m}$, respectively.

\section{RELATIONSHIP BETWEEN CUMULATIVE RAINFALL AND GROUNDWATER LEVEL}

Generally, the rainfall intensity and cumulative rainfall are the two critical factors that affect the safety of a slope. However, the groundwater level induced by rainfall directly impacts the safety of a slope. When the groundwater level in a slope exceeds a threshold value, the factor of safety of the slope is less than 1.0, and the slope movement occurs. Hence, the collected data of the groundwater level in a slope may be used to evaluate the stability of a slope. Moreover, the existing water content of a slope also affects the groundwater level fluctuation during a rainfall event. For a slope, different patterns of rising groundwater levels are possible for the rainfalls after a long period of drought or in a rainy season. Therefore, the cumulative rainfall of both the current rainfall event and the antecedent rainfall events should be considered when the effect of the rainfall on the groundwater level is investigated.

In Fig. 8, a continuous rainfall event is defined by separating the antecedent rainfall from the next rainfall event (Ishikawa 1990). Ishikawa (1990) defined the antecedent rainfall as the rainfall happening within 14 days $(336 \mathrm{~h})$ before the start of a continuous rainfall event. The influence of the antecedent rainfall on the groundwater level reduces with increasing time before the continuous rainfall event. The effective antecedent rainfall $\left(R_{W A}\right)$, which involves the total effect of antecedent rainfalls, is calculated as

$R_{W A}=\alpha_{1} d_{1}+\alpha_{2} d_{2}+\cdots \cdots+\alpha_{14} d_{14}=\sum_{n=1}^{14} \alpha_{n} d_{n}$

where $\alpha_{n}$ is the recession coefficient, $\alpha_{n}=\frac{1}{2}^{\left(\frac{n}{T}\right)}$, T is the days of half-life time, $n$ is the $n$th day before a continuous rainfall event $(n=1-14)$, and $d_{n}$ is the rainfall on the $n$th day before a continuous rainfall event $(\mathrm{mm})$.

In this study, the material of test slope is colluvium, and its permeability is good. In Fig. 5a, the antecedent rainfall has insignificant impacts to the groundwater level fluctuation in BH-B because the groundwater level increases and drops dramatically during and after heavy rainfalls, respectively. Therefore, 14 days for calculating antecedent rainfall is too long for the test slope. To simplify the calculation of the effect of antecedent rainfall, only the antecedent rainfall within five days $(120 \mathrm{~h})$ before the start of the rainfall event is considered.

Figure 9 shows the total cumulative rainfall $(\Sigma R)$, 
Table 1. Parameters used in Geo-Studio analysis (Chen 2018).

\begin{tabular}{|c|c|c|c|c|c|c|c|c|c|c|}
\hline Parameter & $\begin{array}{c}\text { Unit weight } \\
\gamma\left(\mathbf{k N ~ m}^{-3}\right)\end{array}$ & $\begin{array}{l}\text { Cohesion } \\
\text { c (kPa) }\end{array}$ & $\begin{array}{c}\text { Friction } \\
\text { angle } \phi\left(^{\circ}\right)\end{array}$ & $\begin{array}{c}\text { Saturated } \\
\text { volumetric water } \\
\text { content }\left(\mathbf{m}^{3} \mathbf{~ m}^{-3}\right)\end{array}$ & $\mathrm{D}_{10}(\mathrm{~mm})$ & $\mathrm{D}_{60}(\mathrm{~mm})$ & $\begin{array}{c}\text { Plastic } \\
\text { limit PL } \\
(\%)\end{array}$ & $\begin{array}{l}\text { Liquid limit } \\
\text { LL (\%) }\end{array}$ & $\begin{array}{c}\text { Hydraulie } \\
\text { conductivity } \\
\mathrm{k}\left(\mathrm{m} \mathrm{s}^{-1}\right)\end{array}$ & $\begin{array}{c}\text { Slope stability } \\
\text { analysis }\end{array}$ \\
\hline Colluvium & 21 & 12 & 33 & 0.45 & 0.15 & 3.4 & 18.1 & 31 & $1.01 \times 10^{-4}$ & $\begin{array}{l}\text { Morgenstern- } \\
\text { Price Method }\end{array}$ \\
\hline
\end{tabular}
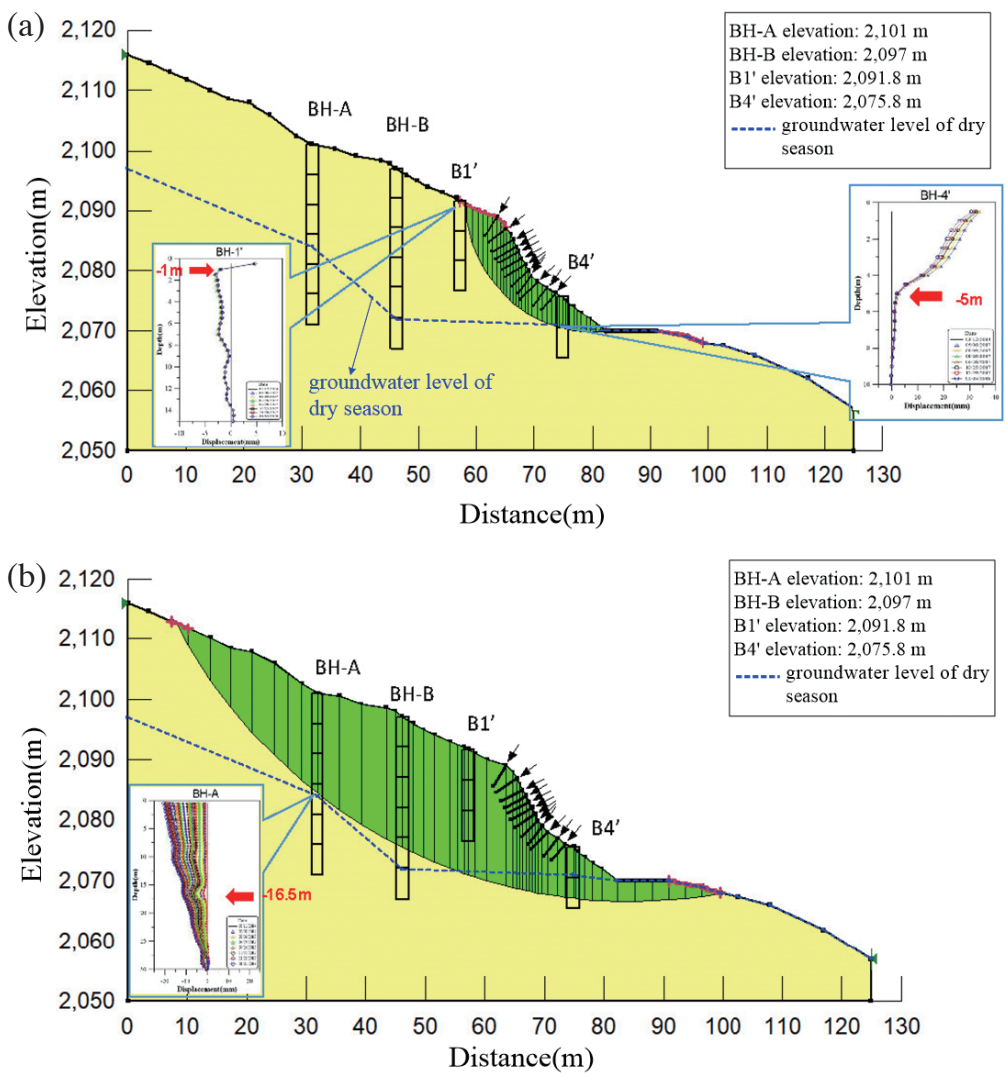

Fig. 6. The two possible slope failure patterns of test slope; (a) Shallow collapse (first sliding surface); (b) Deep-seated landslide (second sliding surface).

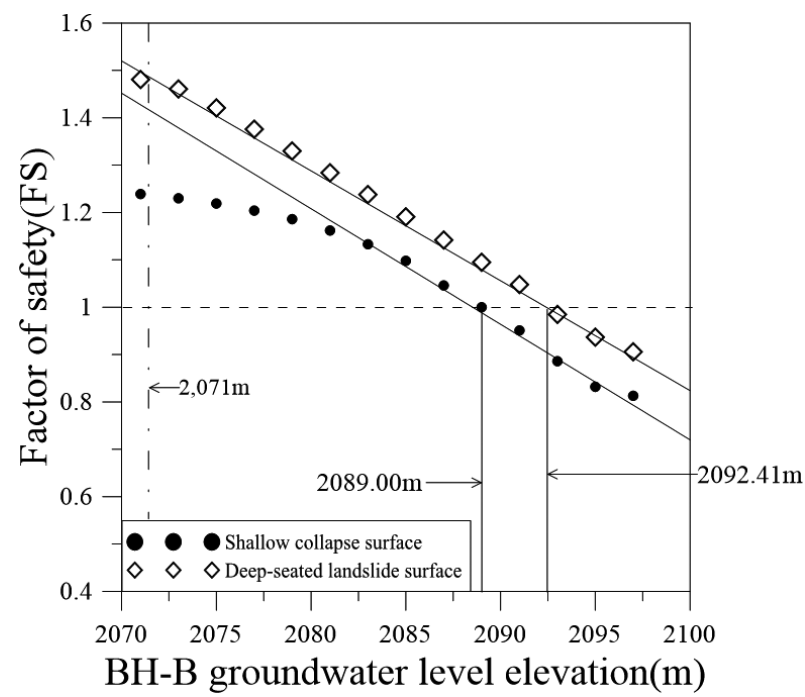

Fig. 7. Relationship between groundwater level elevation and factors of safety of the two potential sliding surfaces. 


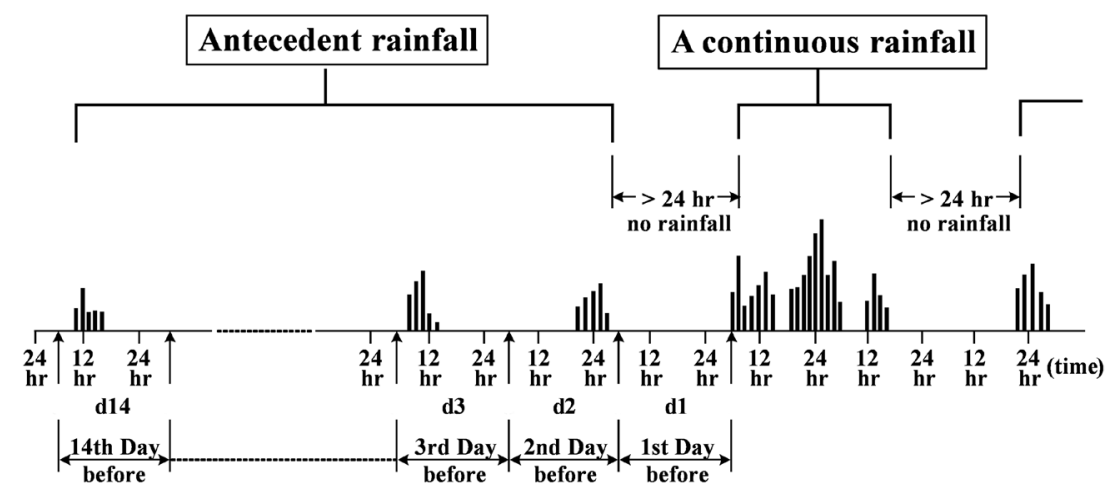

Fig. 8. The concept diagram of a continuous rainfall and previous rainfall (Ishikawa 1990).

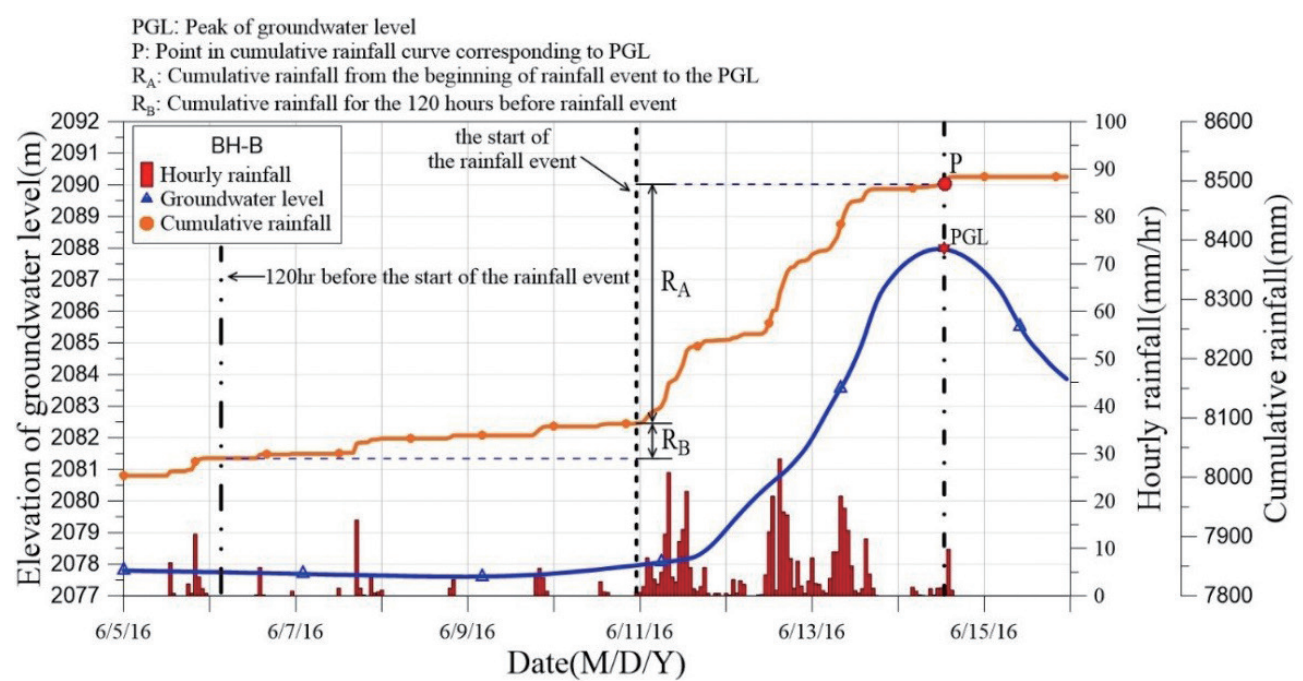

Fig. 9. Schematic diagram of antecedent rainfall $\left(R_{B}\right)$ and total cumulative rainfall $\left(\Sigma R=R_{A}+R_{B}\right)$.

which raises the groundwater level to a peak point (PGL), is determined for two parts of the cumulative rainfall, $R_{A}$ and $R_{B}$. The time of the peak groundwater level (PGL) coincides to the converging point $(P)$ of the cumulative rainfall curve. Therefore, $R_{A}$ is the cumulative rainfall from the start of the rainfall event to the time when the groundwater level reaches the peak point (PGL). In addition, the cumulative rainfall is set to be $R_{A}$ when the groundwater data are unavailable. $R_{B}$ is the antecedent cumulative rainfall within $120 \mathrm{~h}$ before the rainfall event.

According to the rainfall records of the Alishan Rainfall Station from 2014 to 2017, only the total cumulative rainfalls of these rainfall events resulting in a significant increase of the groundwater level in the test slope (BH-B is the representative well) were selected, including 13 rainfall events from the plum rain fronts (Table 2) and 10 rainfall events from typhoons (Table 3). Based on Tables 2 and 3 , the total cumulative rainfall $(\Sigma R)$ and the elevation of the peak groundwater level (PGL) for each of these rainfall events are plotted, and a regression equation [Eq. (2)] is ob- tained (in reference to the solid line in Fig. 10).

$\mathrm{PGL}=0.0242 \times \Sigma R+2075.2 \quad\left(R^{2}=0.74\right)$

where PGL is the elevation of the peak groundwater level $(\mathrm{m})$, and $\Sigma R$ is the total cumulative rainfall $(\mathrm{mm})$.

Figure 11 shows the upper bound and the lower bound of the selected data by shifting the regression line (from the data in Fig. 10) up and down to form the upper and lower envelopes of the data. In Fig. 11, the meaning of upper bound and lower bound is that, when $\Sigma R=r$, the maximum PGL of $\mathrm{BH}-\mathrm{B}$ can reaches the maximum point $u$ but is impossible to exceed the point $u$. Therefore, the upper bound in Fig. 11 is considered to be the maximum limit of PGL under different $\Sigma R$ at BH-B. The probability of the PGL to reach the upper bound and its upper left space is $0 \%$. Contrarily, when $\Sigma R=$ $r$, the PGL of BH-B at least reaches point $l$ in Fig. 11. Therefore, the probability of the PGL to reach the lower bound and its right lower space is $100 \%$. 


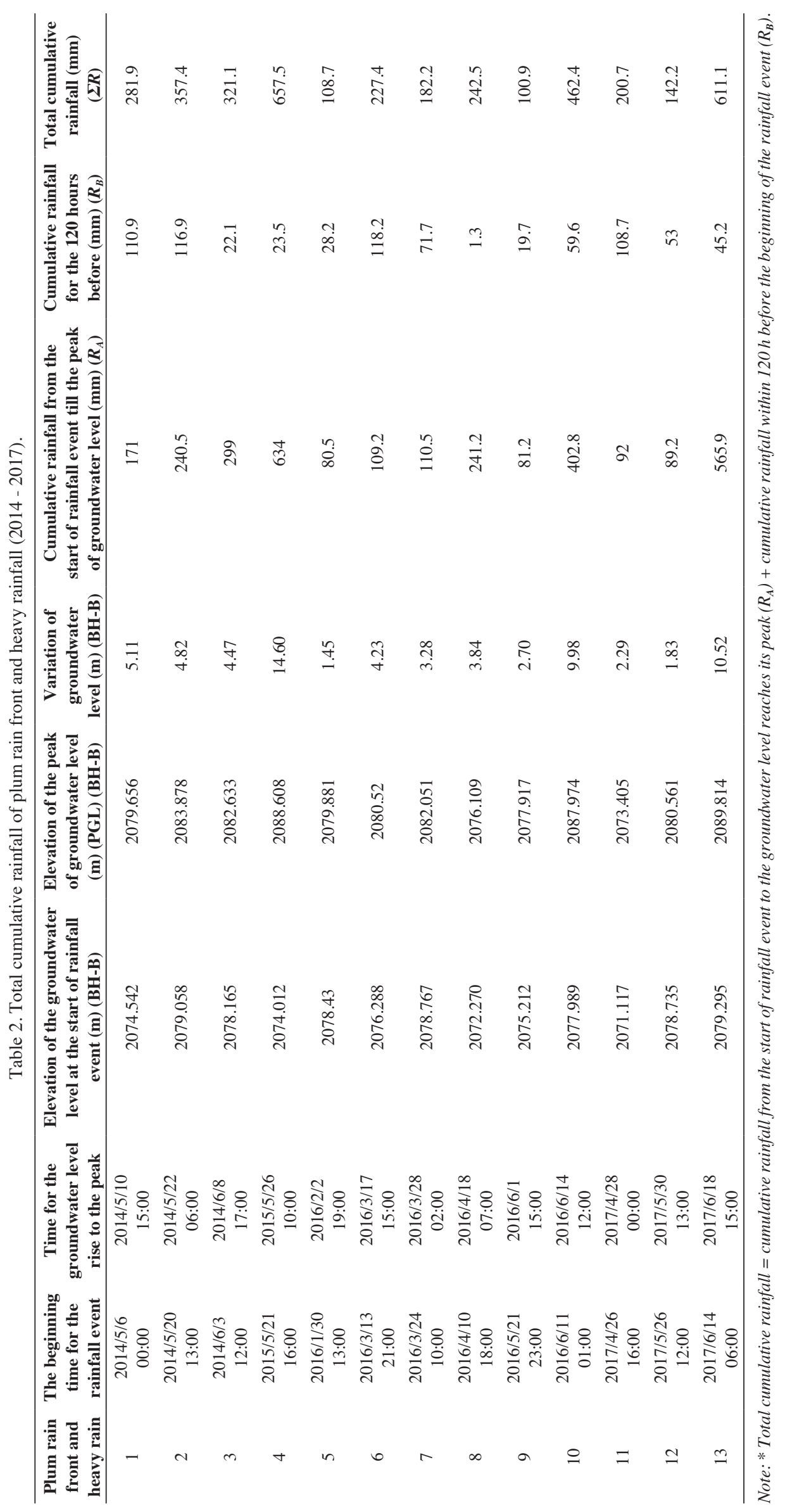




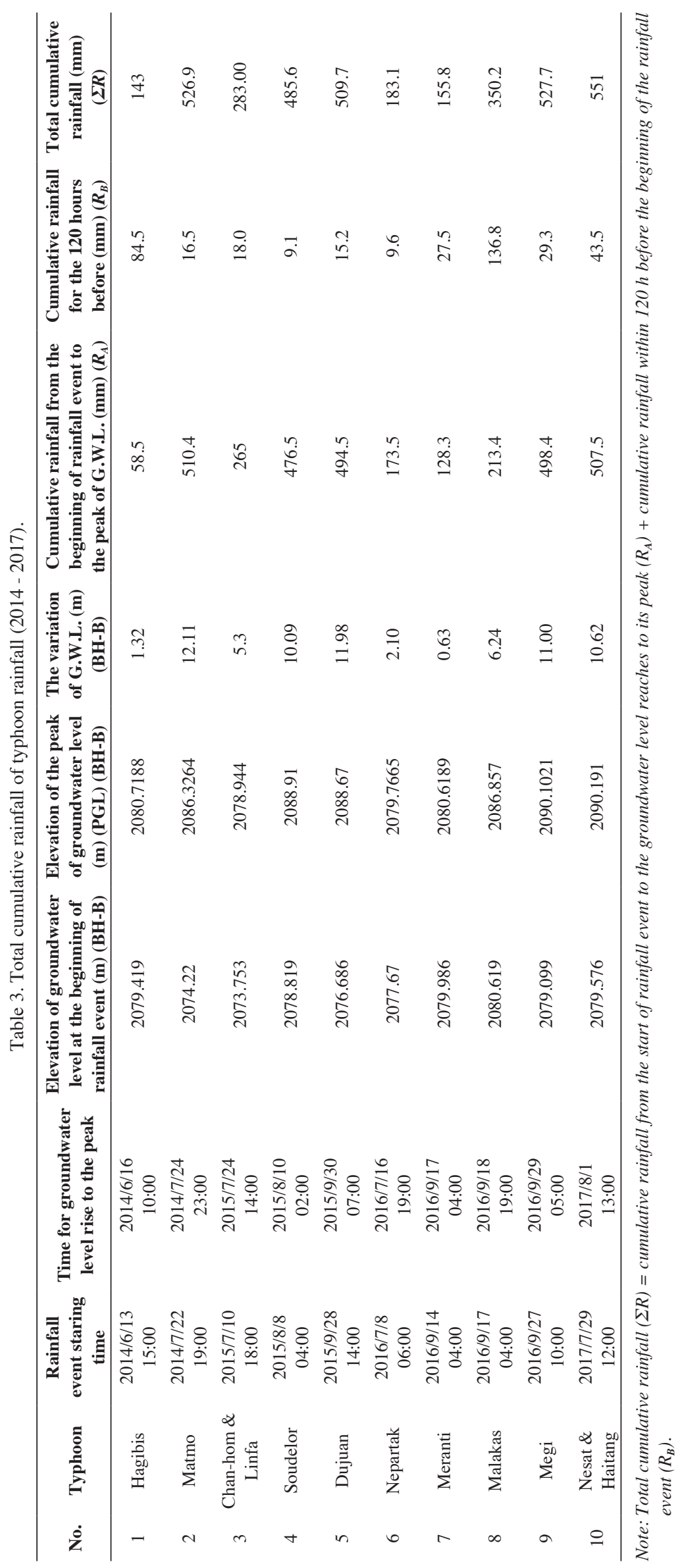




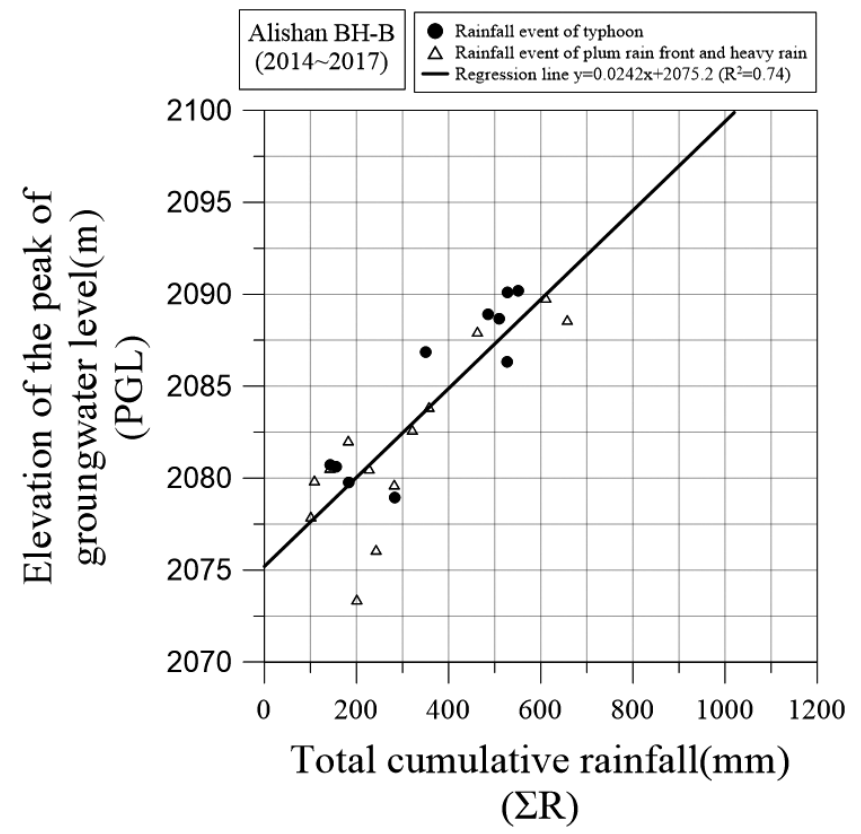

Fig. 10. The peak of groundwater level (PGL) of different rainfall events (BH-B, 2014 - 2017).

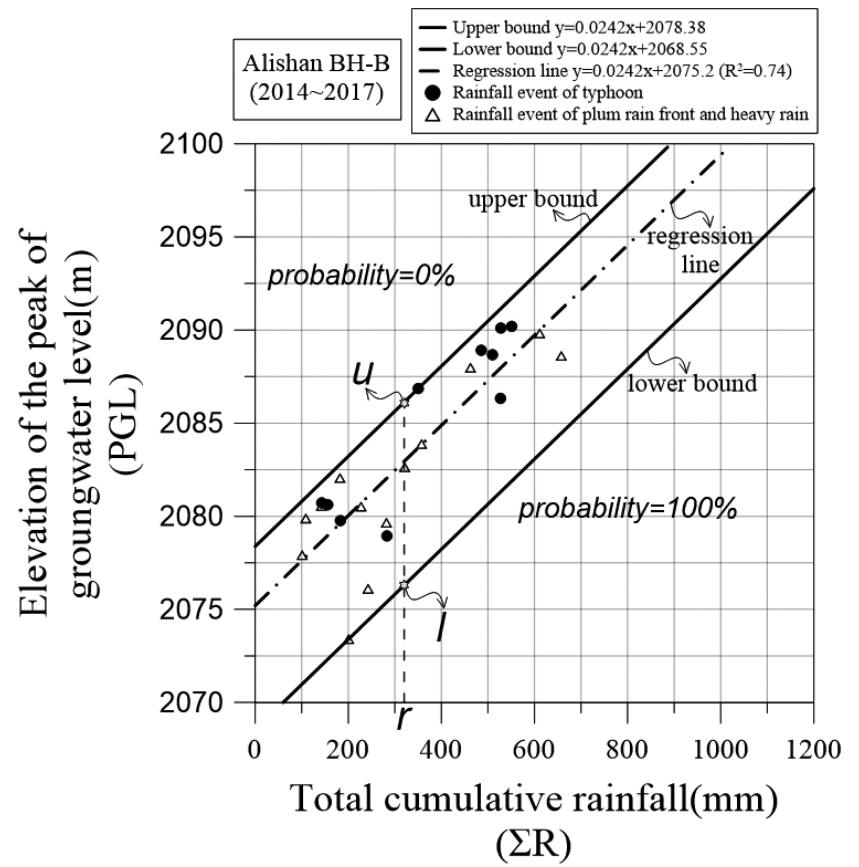

Fig. 11. The upper and lower bounds of the PGL distributions under different rainfall events between 2014 and 2017. 
In Fig. 12, since the 23 data of PGL distribute between the upper and the lower bounds can be used to evaluate the probability of the PGL in the space between the upper and lower bounds. Assume the PGL probability is $30 \%$, and the line of the PGL probability $=30 \%$ is parallel to the upper bound (probability is $0 \%$ ). The number of PGL data between the lines of probability $30 \%$ and probability $0 \%$ have $23 \times 30 \%=6.9 \fallingdotseq 7$ data. The same idea can be extended to get the lines for PGL probability $=60 \%$ and $90 \%$, respectively in Fig. 12.

\section{DEVELOPING A RAINFALL-BASED EARLY WARNING CRITERIA}

According to the slope stability analysis results (Fig. 7), the safety factor of the first sliding surface (shallow collapse surface) will be reduced to 1.0 if the representative groundwater level of the test slope in $\mathrm{BH}-\mathrm{B}$ rises to an elevation of $2089.0 \mathrm{~m}$. Then, a shallow collapse may occur along the first sliding surface. Similarly, the safety factor of the second sliding surface will be decreased to 1.0 when the groundwater level rises to $2092.41 \mathrm{~m}$, and a deep-seated landslide (along the second sliding surface) may be induced.

Now, based on the Fig. 12, draw a horizontal line with PGL $=2089.0 \mathrm{~m}$ to intersect the probability lines at a $($ probability $=0 \%), \mathrm{i}_{3}($ probability $=30 \%), \mathrm{i}_{6}($ probability $=$ $60 \%), i_{9}($ probability $=90 \%)$, and $\mathrm{c}($ probability $=100 \%)$ in Fig. 13a. Obtain the $\Sigma R$ corresponding to each intersecting point. Then, the relation of probability v.s. $\Sigma R$ with PGL = $2089.0 \mathrm{~m}$ is plotted in Fig. 13b.
The meaning of points a and a' in Figs. 13a and b are that if the total cumulative rainfall $(\Sigma R)$ of a rainfall event is less than $439 \mathrm{~mm}$, it is impossible to create a shallow collapse in the test slope. Since, if $\Sigma R<439 \mathrm{~mm}$, the probability of groundwater level raises to $2089.0 \mathrm{~m}$ is $0 \%$. On the other hand, points c and c' in Figs. 13a and b show that when the total cumulative rainfall $(\Sigma R)$ of a rainfall event is greater than $845 \mathrm{~mm}$, the probability to occur a shallow collapse in the test slope is $100 \%$. The probability to induce a shallow collapse will increase from 0 to $100 \%$, when the $\Sigma R$ increases from $439 \mathrm{~mm}$ ( $0 \%$ at "a" point) and pass through the $i_{3}(30 \%), i_{6}(60 \%)$, and $i_{9}(90 \%)$ to $845 \mathrm{~mm}(100 \%$ at "c" point).

Therefore, according to the relations between the probabilities to induce a shallow collapse in test slope and the $\Sigma R$, the slope stability can be divided into three stages (Fig. 13).

(1) safe (green $\bigcirc$ ) stage: $\Sigma R<439 \mathrm{~mm}$, the probability of shallow collapse occurrence is $0 \%$.

(2) dangerous (yellow $\bigcirc$ ) stage: $439 \mathrm{~mm} \leq \Sigma R<845 \mathrm{~mm}$, the probability to create shallow collapse changes from 0 to $100 \%$.

(3) disaster (red $\bigcirc$ ) stage: $845 \mathrm{~mm} \leq \Sigma R$, the probability to occur shallow collapse is $100 \%$.

On the same way, based on Fig. 12, plot a horizontal line with PGL $=2092.41 \mathrm{~m}$ to intersect the probability lines at $\mathrm{b}($ probability $=0 \%), \mathrm{j}_{3}($ probability $=30 \%), \mathrm{j}_{6}$ (probability $=60 \%), \mathrm{j}_{9}($ probability $=90 \%)$, and $\mathrm{d}$ (probability $=$ $100 \%$ ) as shown in Fig. 14a. The $\Sigma R$ corresponding to each intersecting point can be obtained. Then, Fig. 14b shows

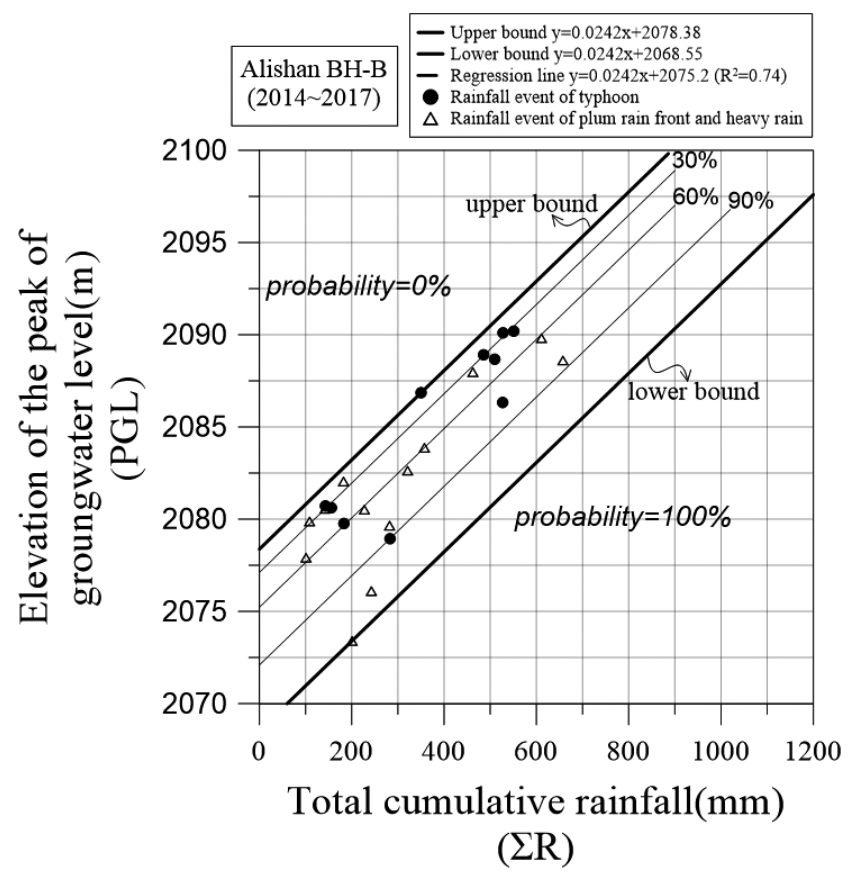

Fig. 12. The probability of PGL between upper and lower bounds. 


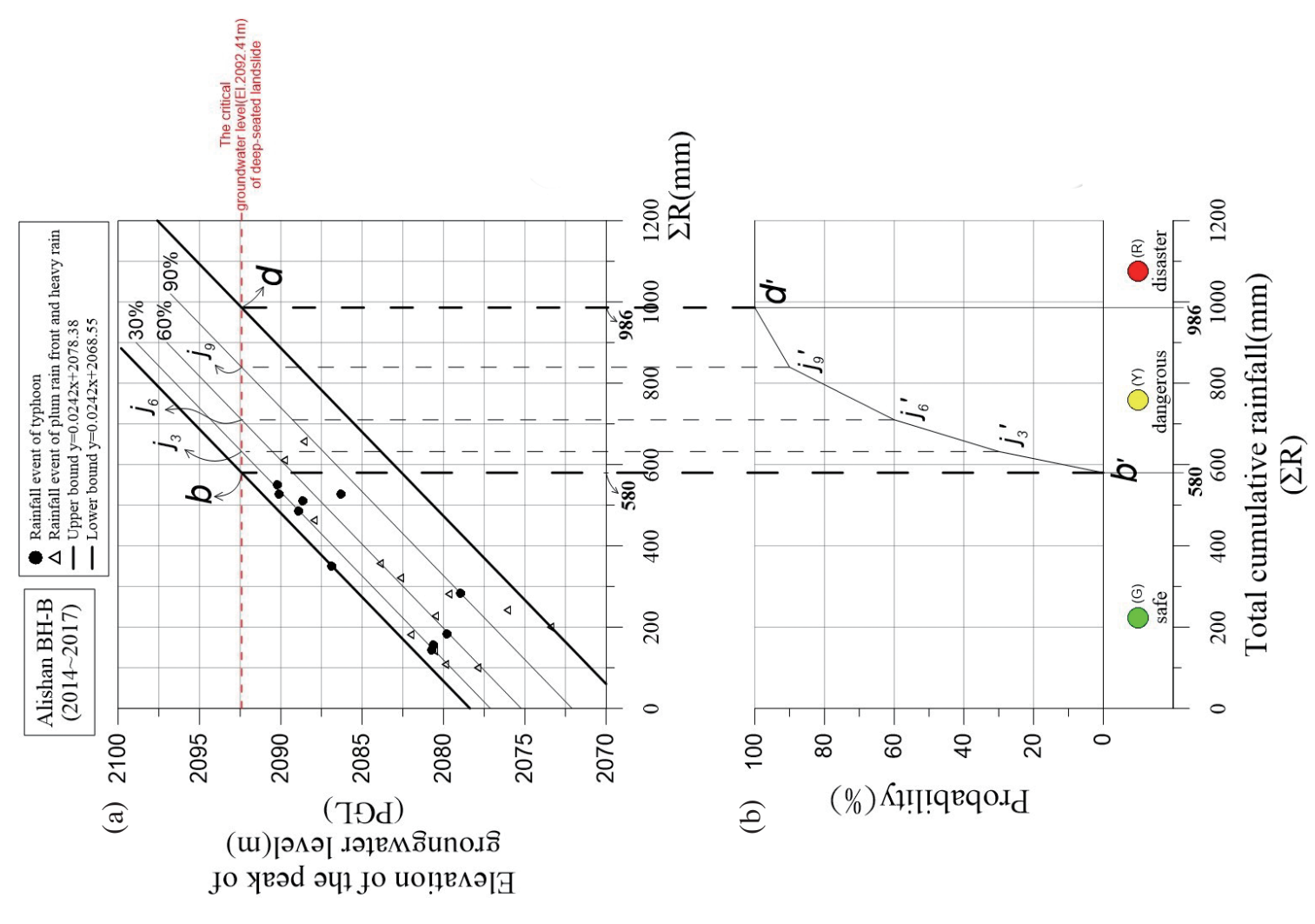

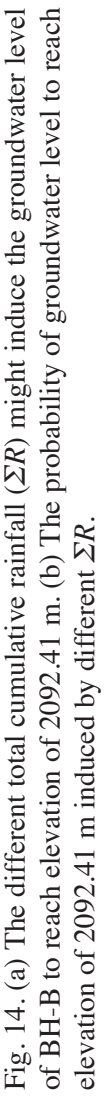

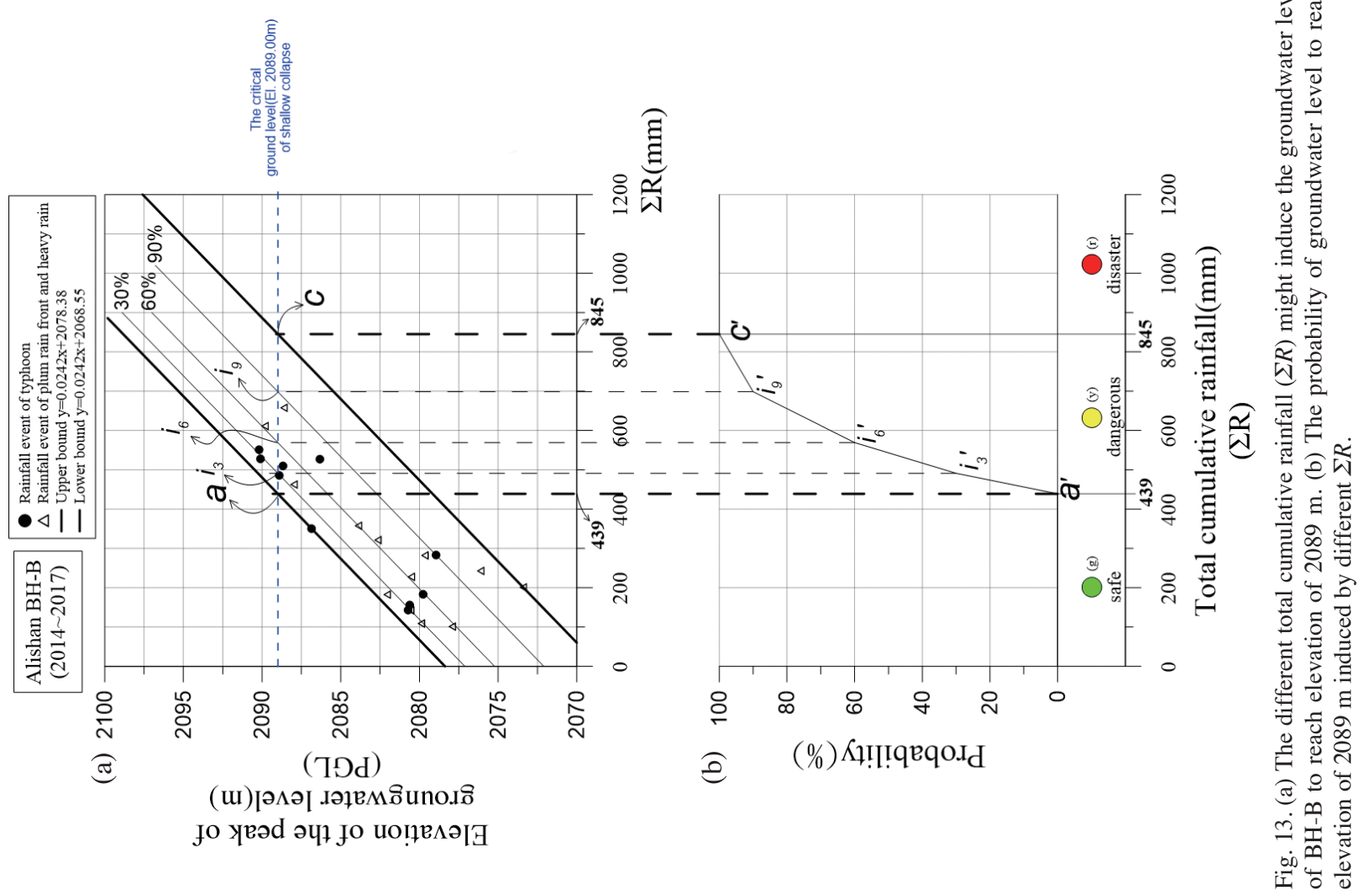


the probability v.s. $\Sigma R$ with PGL $=2092.41 \mathrm{~m}$. The points b and b' in Figs. 14a and b means that the occurrence of a deep-seated landslide is impossible in the test slope if the total cumulative rainfall $(\Sigma R)$ of a rainfall event is less than $580 \mathrm{~mm}$. And, points d and d' in Figs. 14a and b means that the occurrence probability of the deep-seated landslide in the test slope is $100 \%$ when the $\Sigma R$ exceeds $986 \mathrm{~mm}$. The same as Fig. 13b, Fig. 14b shows the following 3 different safety stages based on the occurrence probability of a deepseated landslide in this slope:

(1) safe (Green $\bigcirc$ ) stage: $\Sigma R<580 \mathrm{~mm}$, the probability of happening deep-seated landslide is $0 \%$.

(2) dangerous (Yellow $\bigcirc$ ) stage: $580 \mathrm{~mm} \leq \Sigma R<986 \mathrm{~mm}$, the probability to creat deep-seated landslide increases from 0 to $100 \%$.

(3) disaster $(\operatorname{Red} \bigcirc)$ stage: $986 \mathrm{~mm} \leq \Sigma R$, the probability to induce deep-seated landslide is $100 \%$.

Figure 15a combines the Figs. $13 \mathrm{~b}$ and $14 \mathrm{~b}$ to show the occurrence probability increments of shallow collapse and a deep-seated landslide in the test slope as the increasing $\Sigma R$ of a rainfall event. The changes of probability of a slope failure associating with $\Sigma R$ (Fig. 15a) establish the rainfall-based slope failure criteria of the test slope. In Fig. 15a, the $\Sigma R$ of a rainfall event inducing a shallow collapse and a deep-seated landslide can be divided into five stages:

\section{(1) $\Sigma R<439 \mathrm{~mm}$}

The occurrence probability of shallow collapses is $0 \%$ as safe ( $\bigcirc$ green) stage. In addition, the probability of deepseated landslide is $0 \%$ as safe $(\bigcirc$ Green) stage. Therefore, rainfalls do not induce slope failures.

\section{(2) $439 \mathrm{~mm} \leq \Sigma R<580 \mathrm{~mm}$}

The shallow collapse is in the dangerous ( $\bigcirc$ yellow) stage with occurrence probability between 0 and $62.5 \%$. In addition, the deep-seated landslide is in the safe (O Green) stage with occurrence probability $0 \%$. The rainfalls may trigger shallow collapse but not deep-seated landslide.

\section{(3) $580 \mathrm{~mm} \leq \Sigma R<845 \mathrm{~mm}$}

The shallow collase occurrence probability is between 62.5 and $100 \%$ and is in the dangerous (Oyellow) stage. The occurrence probability of the deep-seated landslide is also in the dangerous ( Yellow) stage between 0 and $90.5 \%$. In the rainfalls, the occurrence probability of the shallow collapse is high and the deep-seated landslide may also occur.

\section{(4) $845 \mathrm{~mm} \leq \Sigma R<986 \mathrm{~mm}$}

The shallow collapse is in the disaster $(\bigcirc$ red) stage with occurrence probability of $100 \%$. In addition, the occurrence probability of the deep-seated landslide is between 90.5 and $100 \%$ and is in the dangerous (O Yellow) stage.

\section{(5) $986 \mathrm{~mm} \leq \Sigma R$}

During the rainfalls, the occurrence probabilities of both shallow collapse and deep-seated landslide are 100\%. The shallow collapse and the deep-seated landslide are in disaster ( red) stage and disaster $(\mathrm{Red})$ stage, respectively.
Finally, the rainfall-based slope failure warning criteria (Fig. 15b) of the study slope are established as follows based on the threat of the slope safety by the $\Sigma R$ in Fig. 15a. In stage (1) $\Sigma R<439 \mathrm{~mm}$, and the slope is classified to be safety ( $\mathrm{gG} \bigcirc$ stage). In stage (2), $439 \mathrm{~mm} \leq \Sigma R<580$ $\mathrm{mm}$, and the slope is classified to be alert (yG $\ominus$ stage). In stage (3), $580 \mathrm{~mm} \leq \Sigma R<845 \mathrm{~mm}$, and the slope is judged as evacuated (yY $\bigcirc$ stage). In stage (4), $845 \mathrm{~mm} \leq \Sigma R<$ $986 \mathrm{~mm}$, and the slope is classified to be in disaster ( $\mathrm{rY} \ominus$ stage). In stage (5, $986 \mathrm{~mm} \leq \Sigma R$ and the slope is classified to be catastrophe ( $\mathrm{rR} \bigcirc$ stage). Table 4 shows the conclusions of the new warning criteria.

\section{VALIDATION OF THE RAINFALL-BASED SLOPE FAILURE WARNING CRITERIA}

The typhoon rainfall-induced slope failure data (1996 - 2010) at the high altitude section $(78.8-96 \mathrm{~km})$ of the Alishan Highway listed in the document (Lee et al. 2013) are used to verify the feasibility of the proposed warning criteria (Fig. 15b and Table 4) for the test slope. The typhoon rainfall-induced slope failure data in Table 5 (Lee et al. 2013) included the cumulative rainfall parameters $R_{A}$, $R_{B}$, and $\Sigma R=R_{A}+R_{B}$, the numbers of slope failures, the total volume of slope failure $(\Sigma V)$ and the average volume of slope failure $\left(V_{a v e}\right)$. Surely, the groundwater variations at BH-B during the rainfalls of these typhoons (Table 4) were unavailable. $R_{A}$ is set to be the cumulative rainfall when the groundwater data at $\mathrm{BH}-\mathrm{B}$ of a rainfall event is unavailable because Fig. 9 shows the time with the peak groundwater level at BH-B coincides to the converging cumulative rainfall during a rainfall event.

From Table 5, four typhoon events (typhoon number $2,4,6,10)$ without landslide occurrence and eight typhoon events (typhoon number 1, 5, 7, and 9, as well as, 11, 12, 17 , and 18) with significant disaster records are selected to rank based on $R_{A}$ in Fig. 16. For each typhoon, the $\Sigma R=$ $R_{A}+R_{B}$, numbers of slope failures, total volume of slope failure $(\Sigma V)$, and average volume of slope failure $\left(V_{\text {ave }}\right)$ are listed at the upper part of Fig. 16. At the lower parts of the Fig. 16, the warning criteria developed in this study divided the rainfall into 5 stages as: (1) safety, gG stage, (2) alert, yG stage, (3) evacuated, yY stage, and (4) disaster, rY stage, (5) catastrophe, rR stage.

Based on the warning criteria developed in Fig. 16, the $\Sigma R=R_{A}+R_{B}$ of Typhoon No. 18 is in the (1) safety gG stage. The $\Sigma R$ of Typhoons No. 11 and No. 7 are in the (4) disaster, rY stage and (2) alert, yG stage, respectively. The $\Sigma R$ of Typhoons No. 9, 5, and No. 12 are classified to be in the (3) evacuated, yY stage. The $\Sigma R$ of Typhoons No. 1 and 17 are in (5) catastrophe, rR stage. Meanwhile, Table 5 and Fig. 16 also show four typhoons (typhoon number 2, 4, 6, and 10) without slope failure at the study highway section. Except the Typhoon No. 10, the new warning criteria 
predict the stable slope during typhoons with the accuracy rate of 75\%. In Fig. 16 and Table 4, in the (2) stage "alert" (stage "yG"), the occurrence probability of the shallow collapse is 0 to $62.5 \%$ but no deep-seated landslide. The rainfall in the Typhoon No. 7 belongs to the stage, it created 11 shallow collapses with $V_{\text {ave }}=43.09$ $\mathrm{m}^{3}$, but no deep-seated landslide occurred. In the (3) stage "evacuated" (stage "yY"), the occurrence probabilities of the shallow collapse and the deep-seated landslides are 62.5 to $100 \%$ and 0 to $90 \%$, respectively. The rainfall in the Typhoons No. 9, No. 5, and No. 12 belongs to the (3) stage "yY". The Typhoons No. 9 triggered 6 shallow collapses with $V_{\text {ave }}=135.8 \mathrm{~m}^{3}$. The rainfall in the Typhoon No. 12 also triggered 6 shallow collapses with $V_{\text {ave }}=$ $327.67 \mathrm{~m}^{3}$. But, the scale of slope failures of Typhoons No. 9 and No. 12 are bigger than that of Typhoon No. 7 (2) stage "yG"). The rainfall in Typhoon No. 5 induced 26 slope failures with $V_{a v e}=583.8 \mathrm{~m}^{3}$. The total volume of the slope failures is $15179 \mathrm{~m}^{3}$. Therefore, the rainfall triggered a lot of shallow collapses and may be a deep-seated landslide with volume near $10000 \mathrm{~m}^{3}$. It is obvious that the new warning criteria can predict the probability of the slope failure patterns (shallow collapse or deep-seated landslide) and the severity of the slope failure impact to the highway.

Finally, the slope failure and blocked traffic at $78.3 \mathrm{~km}$ of the Alishan Highway, which is $8.6 \mathrm{~km}$ away from the study site, on 18 May 2019 is a case study to verify the feasibility of the new warning criteria. On that day, the rainfall recorded at the Alishan rainfall station (Fig. 17) showed the cumulative rainfall from the start of the rainfall event, from 4:00 a.m. to 4:00 p.m., was $397.5 \mathrm{~mm}$. The cumulative rainfall $120 \mathrm{~h}$ prior to the rainfall event was $R_{B}=55 \mathrm{~mm}$. Therefore, he total cumulative rainfall was $\Sigma R=425.5 \mathrm{~mm}$. According to the warning criteria of this study, the rainfall event belongs to the (2) "alert" stage, "yG" stage. In this stage, the shallow collapse may occur without the deepseated landslide. And, the slope failure is a shallow collapse and its failure volume is about $200 \mathrm{~m}^{3}$.

\section{CONCLUSIONS}

This study established an empirical rainfall-based slope failure warning criteria by exploring the relationship between the groundwater level fluctuation and rainfall, and numerically analyzed relation between the groundwater level and the slope stability on the Alishan Highway at the mileage of $86 \mathrm{~km}$ and $950 \mathrm{~m}$. The following conclusions were reached:

(1) The borehole drilling data indicate that the slope is consisted of thick colluvium. The slope stability analysis

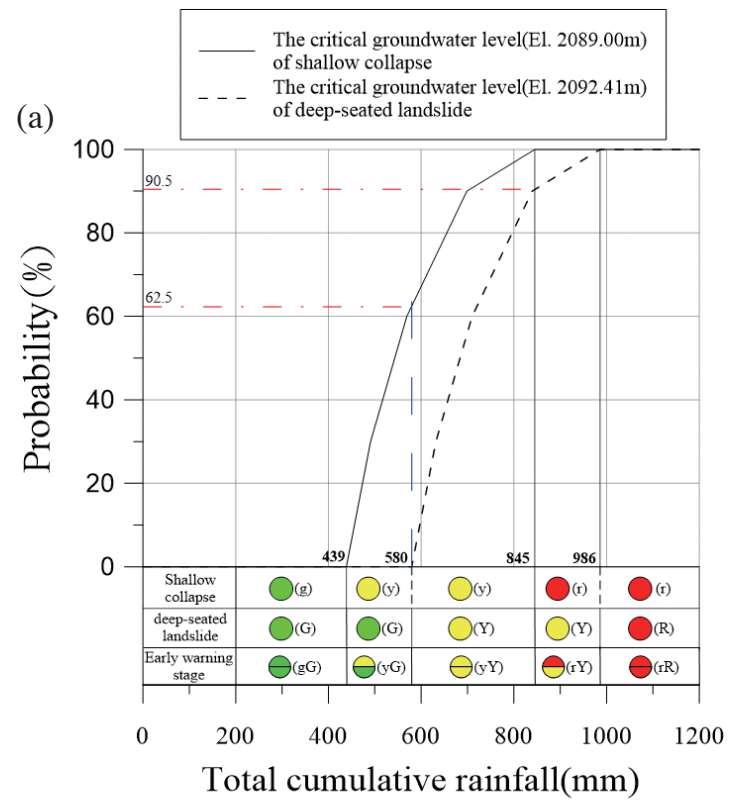

(b)

$(\Sigma \mathrm{R})$

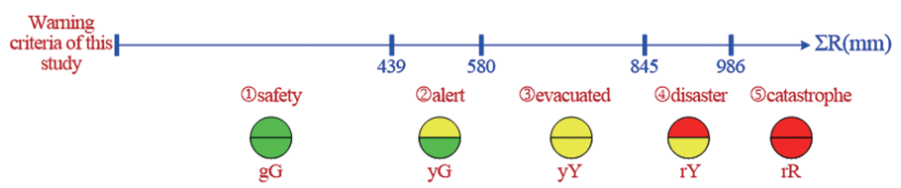

Fig. 15. (a) The probability to occur shallow collapse and deep-seated landslide under different total cumulative rainfall $(\Sigma R)$. (b) The rainfall-based slope failure warning criteria of test slope. 


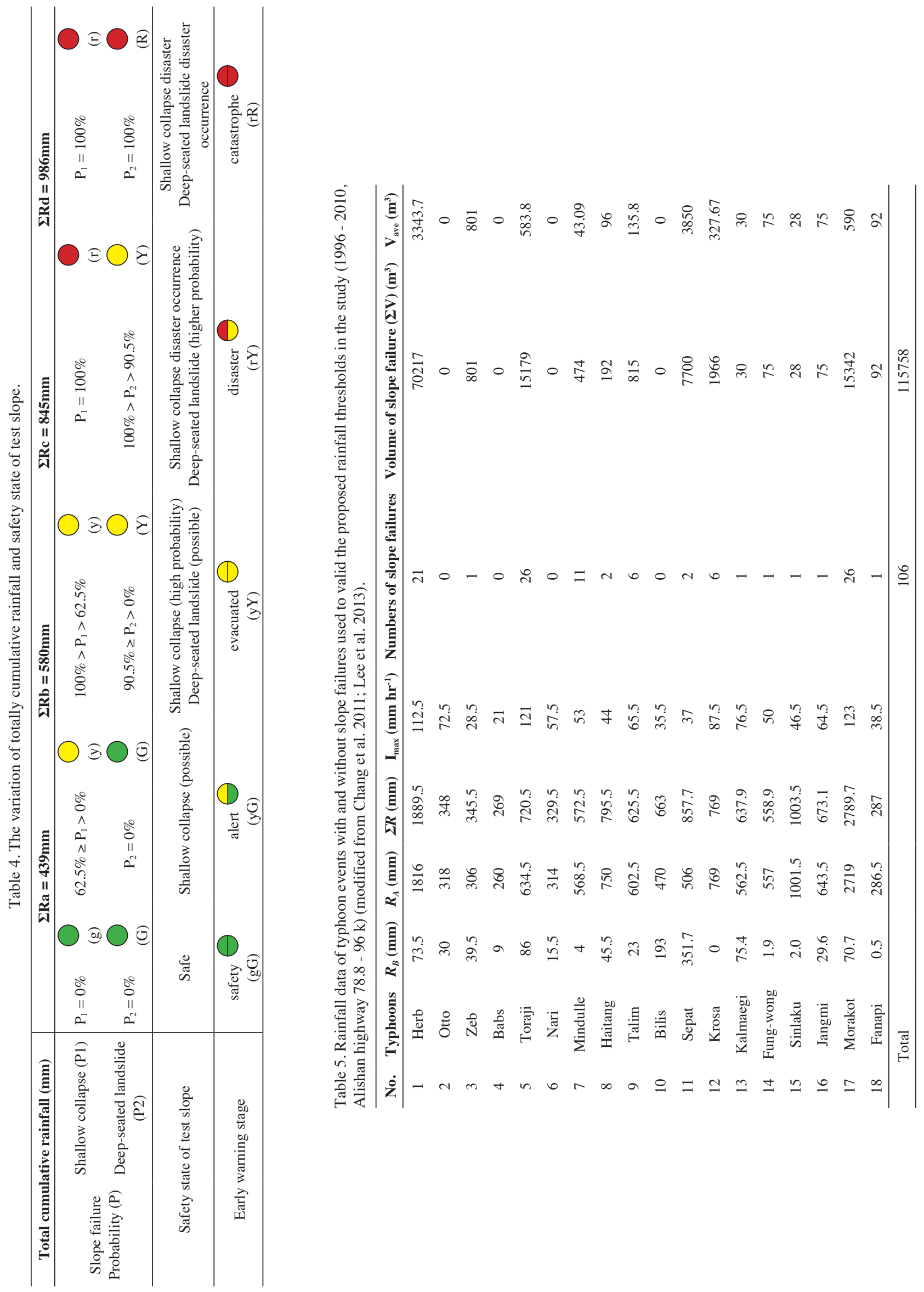




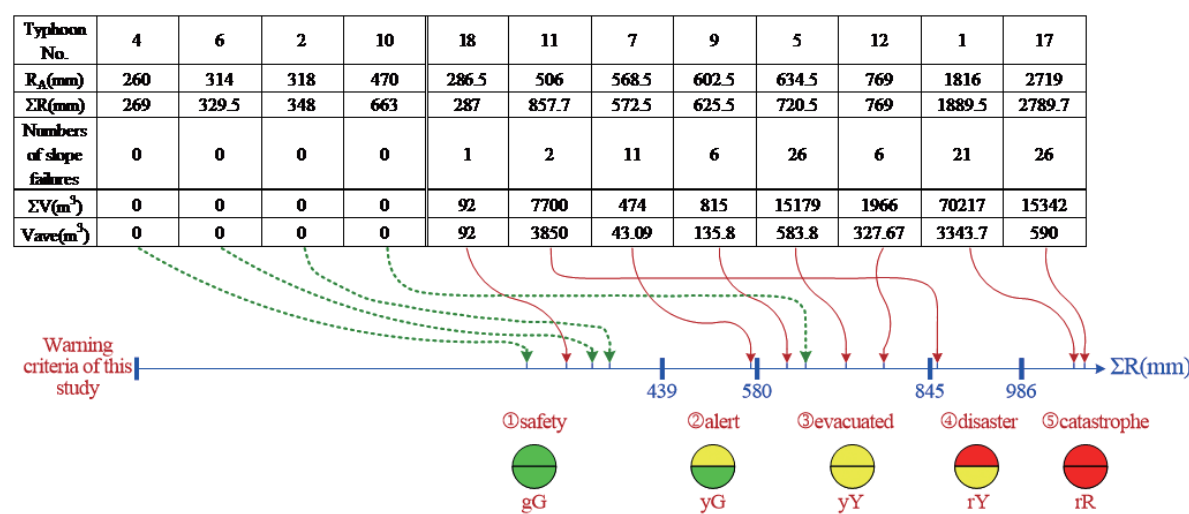

Fig. 16. The validation of the warning criteria of this study by using the data of typhoons with and without disaster (1996 - 2010).

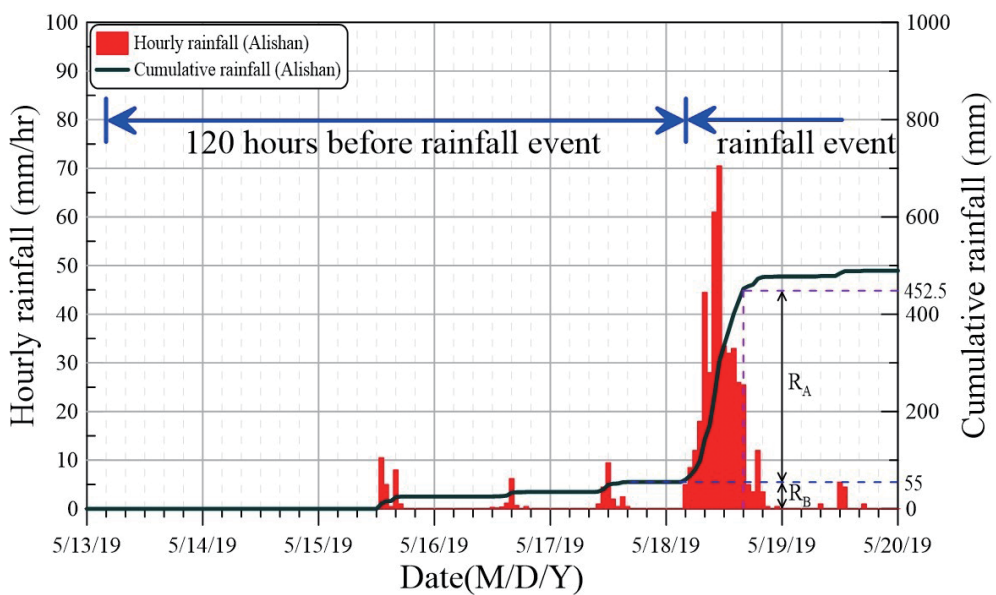

Fig. 17. The rainfall data provided from Alishan Rainfall Station (13 May through 20 May 2019).

shows two potential sliding surfaces within the $30 \mathrm{~m}$ below ground surface. A shallow collapse may occur along the first potential sliding surface; while, a deep-seated landslide may occur along the second sliding surface.

(2) This study investigated the impact of groundwater level fluctuation due to rainfall on the safety of the slope. The results show that when the rainfall raises the groundwater level in BH-B to an elevation of $2089.0 \mathrm{~m}$, the factor of safety of the test slope along the shallow collapse surface is reduced to 1.0 (indicating failure). If the groundwater level reaches $2092.41 \mathrm{~m}$, the factor of safety along the second sliding surface (deep-seat landslide surface) also drops to 1.0.

(3) From the rainfall event records from 2014 to 2017 at the Alishan Rainfall Station, the regression relation of the points of the total cumulative rainfall $(\Sigma R)$ and the elevation of the peak groundwater level (PGL) in each rainfall event is shown in Eq. (2).

(4) In a rainfall event, when the total cumulative rainfall $(\Sigma R)$ exceeds $439 \mathrm{~mm}$, the probability of shallow col- lapse in the test slope begins to exceed $0 \%$ and rises to $100 \%$ when $\Sigma R \geq 845 \mathrm{~mm}$.

(5) Regarding the occurrence of a deep-seated landslide in the test slope, when the total cumulative rainfall $(\Sigma R)$ exceeds $580 \mathrm{~mm}$, the probability begins to increase (from zero). When $\Sigma R \geq 896 \mathrm{~mm}$, the probability reaches $100 \%$.

(6) The warning criteria for the failure of test slope during a rainfall event were developed based on the total cumulative rainfall and the probability of shallow collapse and deep-seated landslide. The warning criteria are divided into five stages: safety, alert, evacuated disaster, and catastrophe. To easy remember the warning criteria for the authority officers, the total cumulative rainfall of 439 , 845 , and $986 \mathrm{~mm}$ are modified to be 440,850 , and 990 $\mathrm{mm}$, respectively. Therefore, when the total cumulative rainfall is less than $440 \mathrm{~mm}$, the test slope is in the safety stage. The alert stage is assigned when the total cumulative rainfall is between 440 and $580 \mathrm{~mm}$. The evacuated stage is assigned when the total cumulative rainfall is between 580 and $850 \mathrm{~mm}$. The slope is in the disaster 
stage when the total cumulative rainfall is between 850 and $990 \mathrm{~mm}$. Finally, the catastrophe stage is reached when the total cumulative rainfall exceeds $990 \mathrm{~mm}$.

Acknowledgements The authors acknowledge the Ministry of Science and Technology of Taiwan for financial support on the research (Grant No.: MOST 108-2638-E-008001-MY2, MOST 107-2625-M-006-012).

\section{REFERENCES}

Chang, S.-K., D.-H. Lee, J.-H. Wu, and C. H. Juang, 2011: Rainfall-based criteria for assessing slump rate of mountainous highway slopes: A case study of slopes along Highway 18 in Alishan, Taiwan. Eng. Geol., 118, 63-74, doi: 10.1016/j.enggeo.2011.01.001. [Link]

Chen, H.-L., 2015: Application Study of Non-Frame Method on Slope Remediation of Alishan Highway. Master Thesis, Department of Civil Engineering, National Cheng Kung University, Tainan City, Taiwan, 114 pp. (in Chinese)

Chen, Y.-C., 2018: Using radar-echo rainfall data to establish a slope sliding warning system. Master Thesis, Department of Civil Engineering, National Cheng Kung University, Tainan City, Taiwan. (in Chinese)

Chi, Y.-Y. and Y.-F. Lee, 2013: Assessment of landslide volume for Alishan highway based on database of rainfall-induced slope failure. International Journal of Environmental and Ecological Engineering, 7, 693-698, doi: 10.5281/zenodo.1088432. [Link]

GEO-SLOPE International Ltd., 2012: Stability Modelling with SLOPE/W, An Engineering Methodology, July 2012 Edition, Alberta, Canada.

Guzzetti, F., S. L. Gariano, S. Peruccacci, M. T. Brunetti, I. Marchesini, M. Rossi, and M. Melillo, 2020: Geographical landslide early warning systems. Earth-Sci. Rev., 200, 102973, doi: 10.1016/j.earscirev.2019.102973. [Link]

Haque, U., P. F. da Silva, G. Devoli, J. Pilz, B. Zhao, A. Khaloua, W. Wilopo, P. Andersen, P. Lu, J. Lee, T. Yamamoto, D. Keellings, J.-H. Wu, and G. E. Glass, 2019: The human cost of global warming: Deadly landslides and their triggers (1995-2014). Sci. Total Environ., 682, 673-684, doi: 10.1016/j.scitotenv.2019.03.415. [Link]
Hu, I.-C. and H.-J. Liao, 2010: Method of up-slope mitigation priority for Alishan mountain road in Taiwan. J. Perform. Constr. Facil., 24, 373-381, doi: 10.1061/ (asce)cf.1943-5509.0000110. [Link]

Huang, A.-B., J.-T. Lee, Y.-T. Ho, Y.-F. Chiu, and S.-Y. Cheng, 2012: Stability monitoring of rainfall-induced deep landslides through pore pressure profile measurements. Soils Found., 52, 737-747, doi: 10.1016/j. sandf.2012.07.013. [Link]

Ishikawa, Y., 1990: The alert and refuge guidelines for debris flow based on rainfall. Sinsabo, $\mathbf{4 3}, 40-47$. (in Japanese)

Lee, D.-H., M.-H. Lai, J.-H. Wu, Y.-Y. Chi, W.-T. Ko, and B.-L. Lee, 2013: Slope management criteria for Alishan Highway based on database of heavy rainfallinduced slope failures. Eng. Geol., 162, 97-107, doi: 10.1016/j.enggeo.2013.04.012. [Link]

Lin, H.-M., S.-K. Chang, J.-H. Wu, and C. H. Juang, 2009: Neural network-based model for assessing failure potential of highway slopes in the Alishan, Taiwan area: Pre- and post-earthquake investigation. Eng. Geol., 104, 280-289, doi: 10.1016/j.enggeo.2008.11.007. [Link]

Merz, J., P. M. Dangol, M. P. Dhakal, B. S. Dongol, and R. Weingartner, 2006: Rainfall amount and intensity in a rural catchment of the middle mountains, Nepal. Hydrolog. Sci. J., 51, 127-143, doi: 10.1623/ hysj.51.1.127. [Link]

Shieh, C.-L., C.-M. Wang, W.-C. Lai, Y.-C. Tsang, and S.-P. Lee, 2009: The composite hazard resulted from Typhoon Morakot in Taiwan. Japan Society of Erosion Control Engineering, 62, 61-65, doi: 10.11475/ sabo.62.4_61. [Link]

Wilson, R. C., 1997: Operation of a landslide warning system during the California storm sequence of January and February 1993. In: Larson, R. A. and J. E. Slosson (Eds.), Storm-Induced Geologic Hazards: Case Histories from the 1992-1993 Winter in Southern California and Arizona, Geological Society of America, Boulder, Colorado, USA, 61-70, doi: 10.1130/REG11-p61. [Link]

Zhang, Y., H. Li, Q. Sheng, K. Wu, and G. Chen, 2011: Real time remote monitoring and pre-warning system for highway landslide in mountain area. J. Environ. Sci., 23, S100-S105, doi: 10.1016/s1001-0742(11)61087-5. [Link] 